\title{
FUTURE ANXIETY AMONG THE STUDENTS OF HEARING DISABILITIES IN AL-AMAL SCHOOL FOR THE DEAF AT THE GOVERNORATE OF MUSCAT OMAN

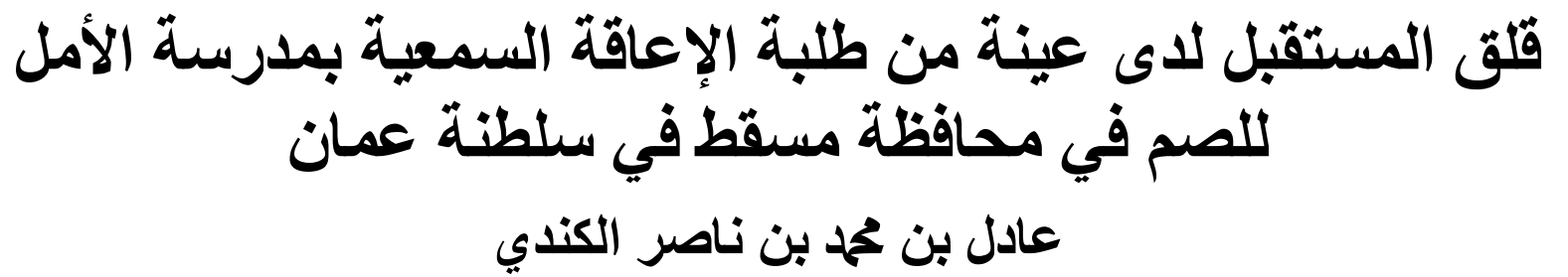

\author{
Adil Mohammed Nasser Alkindi ${ }^{{ }^{*}}$, Prof. Dr. Dawood Abdulmalek Al-Hidabi ${ }^{2}$ and Prof. \\ Dr. Ahmad Jumaa Al-Riymi ${ }^{3}$ \\ ${ }^{1} \mathrm{Ph} . \mathrm{D}$. Candidate at the Faculty of Education, International Islamic University Malaysia (IIUM), \\ Adel.alkindi@moe.om \\ ${ }^{2}$ Prof. Dr. at the Kulliyyah of Education, International Islamic University Malaysia, (IIUM); \\ Dawood@iium.edu.my \\ ${ }^{3}$ Prof. Dr. at the Rustaq College Of Education, Oman: Ahmed.rus@cas.edu.om \\ ${ }^{*}$ Corresponding author
}

\begin{abstract}
This research paper is part of an extensive study conducted by the researcher on parental treatment methods and its relationship to irrational thoughts and future anxiety among a sample of students with hearing impairment. Many of the hearing impaired suffer from some problems that hinder the process of their proper integration with society. As a result of irrational thoughts that cause anxiety in the future, pushing the owner into a state of confusion, pessimism, anticipation of disasters, loss of a sense of security, and fear of family, social and economic problems. Therefore, the study aimed: to diagnose the level of prevalence of future anxiety among students with hearing impairment, and to discuss the relationship between parenting methods as perceived by students with disabilities and the level of prevalence of future anxiety they have. The study adopted the relational descriptive approach. The study population consisted of (100) male and female students at Al-Amal School for grades (7-12), which was adopted as a sample for the study. The researcher built a measure of future anxiety from (21) statements distributed in three dimensions: the health personality, the social family, and the professional economic. The statistical methods that were used: Descriptive analysis, and Pearson correlation coefficient. The results showed: that the level of future anxiety among students with hearing impairment was low. The health personal dimension obtained the highest averages, the social, family dimension, and finally the professional economic dimension.
\end{abstract}

Keywords: hearing impairment, future anxiety, treatment of parents.

الملخص

هذه الورقة البحثية جزءٌ من دراسة موسعة يجريها الباحث حول أساليب المعاملة الوالدية وعلاقيتها بالأفكار اللاعقلانية وقلق المستقبل لدى عينة من طلبة الإعاقة السمعية. حيث يعاني كثيرٌ من المعاقين

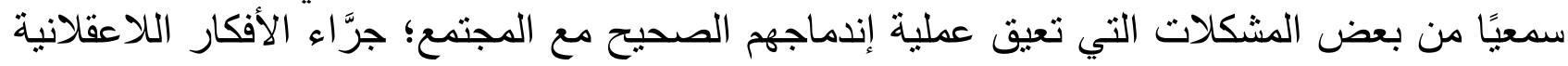


التي تسبب قلق المستقبل، فتدفع بصاحبها لحالة من الارتباك والتشاؤم وتوقع الكوارث وفقدان الثعور

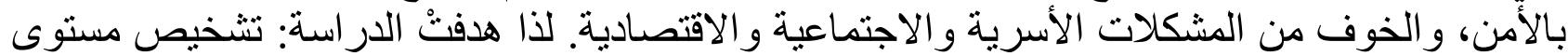

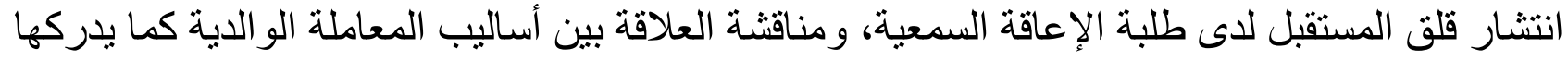

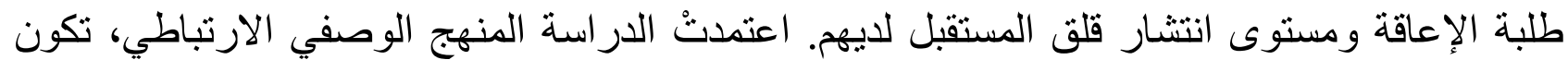

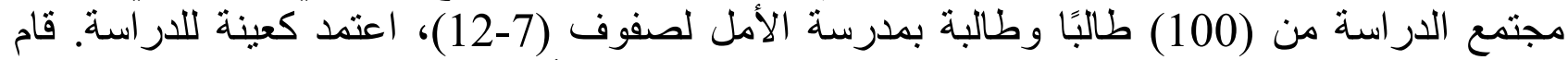

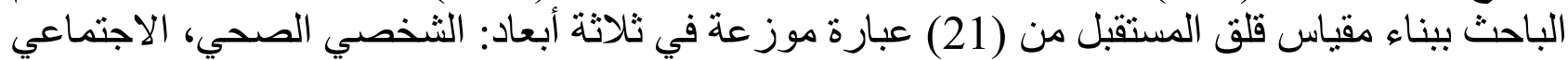

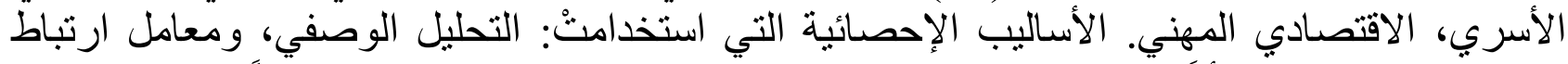

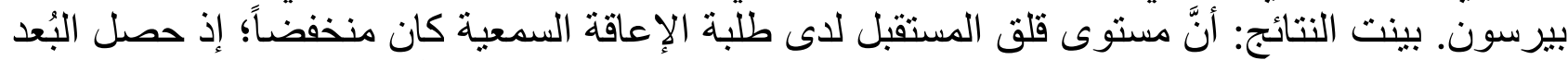
الثخصي الصحي على أعلى المتوسطات، فالبُعد الاجتماعي الاسري، وأخير اً البعد الاقتصادي المئ المهني. كلمات مفتاحية: الإعاقة السمعية، قلق المستقبل، معاملة الو الدين.

المقدمة:

تعد الإعاقة السمعية إحدى أشكال الإعاقات التي يعاني منها ذوو الاحتياجات الخاصة، ومن أكثر ها

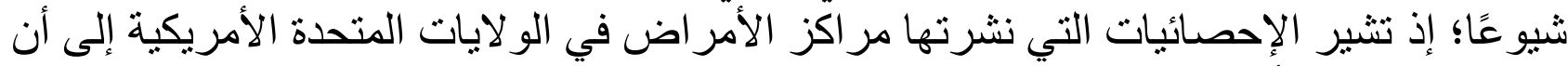

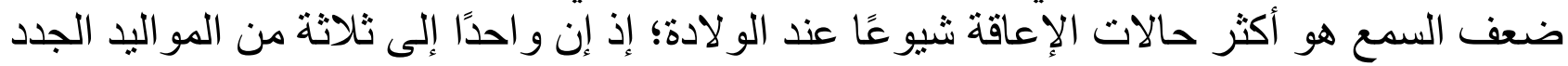

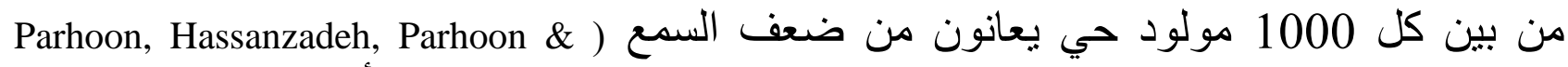

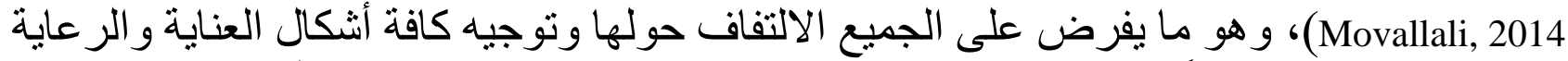
لمن بعانون منها، تحقيقًا للقيم الإنسانية التي تنادي بها فا المجتمعات كافة، من أجل تنمية قدراتها

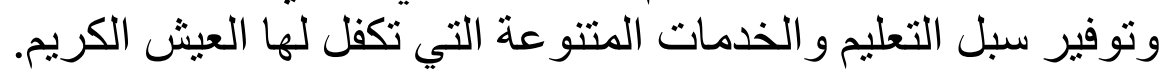

ويشير مصطلح الإعاقة السمعية إلى قصور حاسة السمع لدى المعوق مما يؤثر في قدرته على الإي التو اصل مع الآخرين و الذي ينعكس بدوره على حالته التفسية وتطوره التعليمي و التدريبي (عدائكة

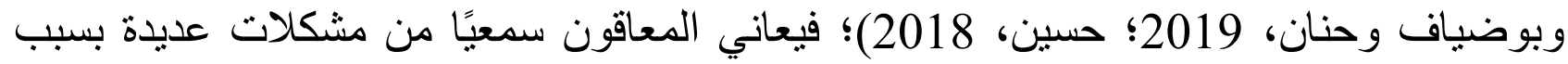

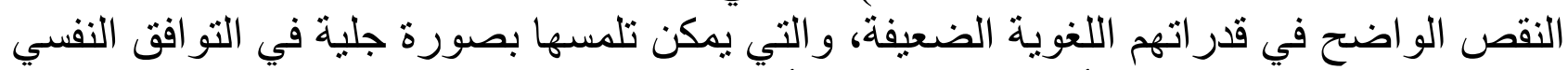
و الاجتماعي سو اء مع ذو اتهم أو حتى مع محيط أسر هم ومجتمعهم المدرسي و المحلي (حمد وبلانل،

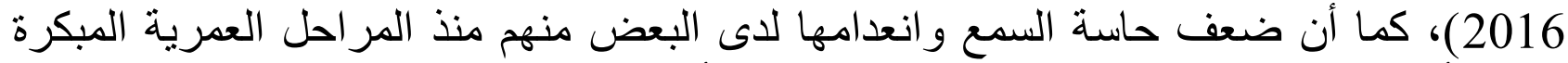
جعلهم أقل قدرة على تلمس مشاعر الآخرين تجاههم أو قراءة ردات فعلهم بصورة منطقية، وهو الأمر الذي ساهم في تكون صور ذهنية عن ذو اتهم و علاقتهم مع الآخرين، وبناء شخصباتهم وفقًا لهذه التصور ات (صنالح، 2014).

ويعدد أبو فضة (2013) مجموعة من الاضطر ابات النفسية التي يعاني منها ذوو الإعاقة السمعية

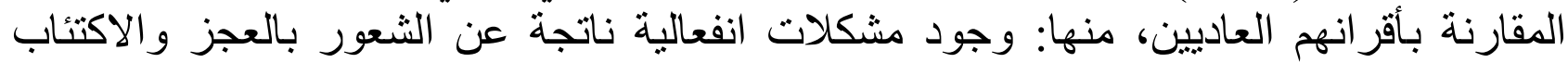

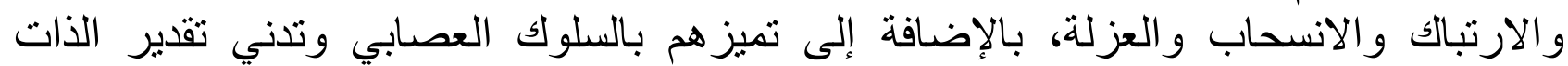

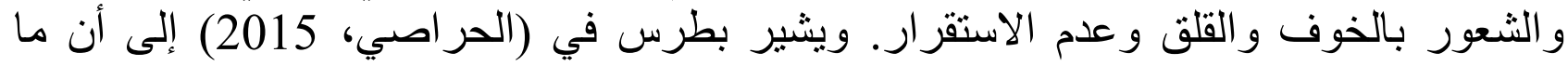
يعانيه المعوق سمعيا من مشكلات، ما هو إلا نتاج لتفاعله مع الوسط البيئي المحيط به وفيه وخاصة الأسرة، وقد وجد أن 90\% من أفر اد أسر المعاقين سمعيا لا يوجد بينهم وبين المعوق سمعيًا نظام تو اصل مناسب، إلا بعض الإيماءات البدائية التي لا تسهم في تطوير قدر اته ومهار ات التواصل اصل 


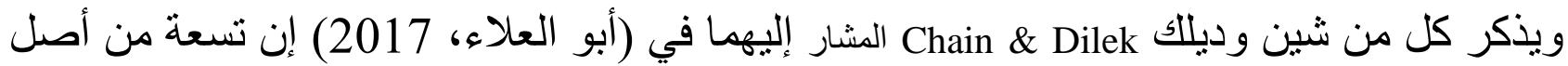

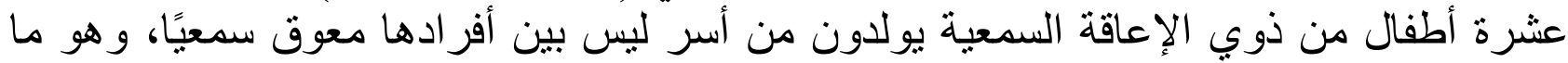

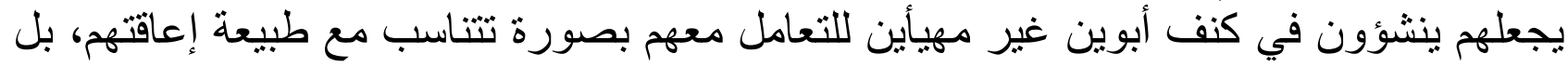

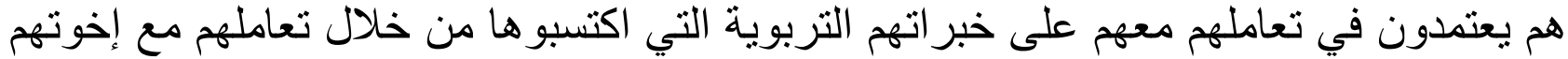

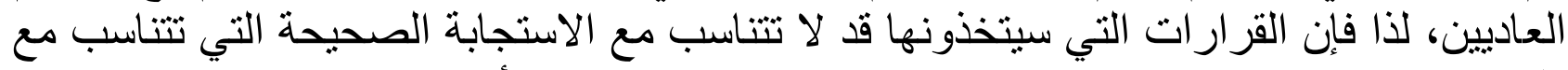

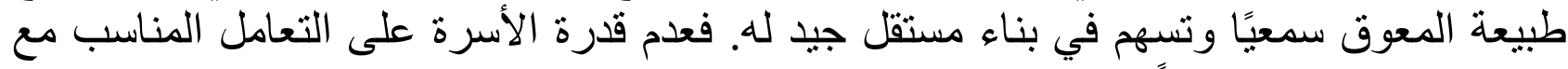

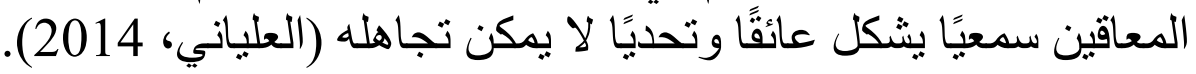

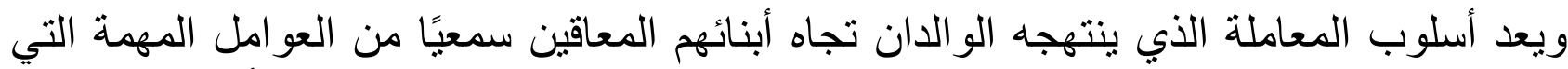

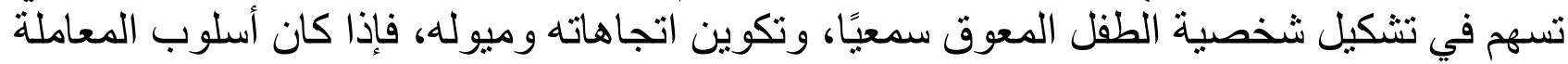

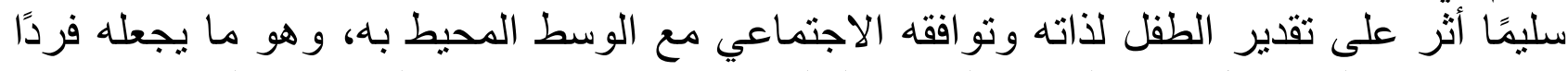

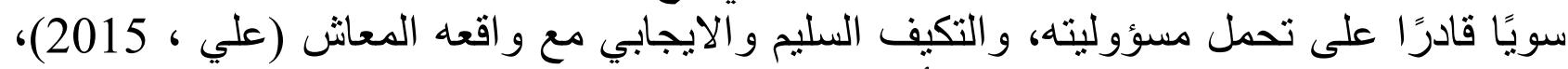

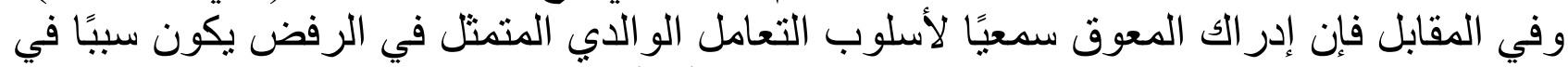

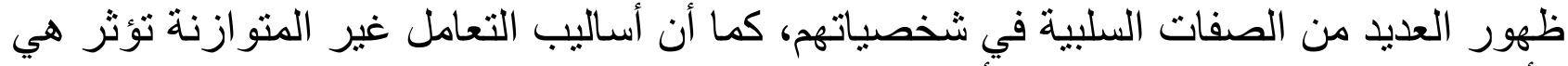
الأخرى فيهم وتعرضهم للإصابة بالأمر اض النفية النفية (الرواحية، 2016).

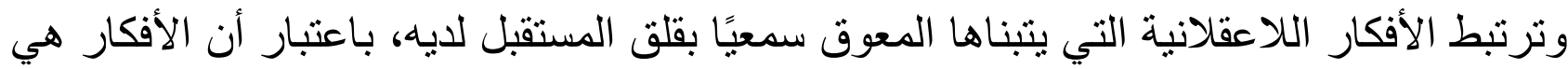

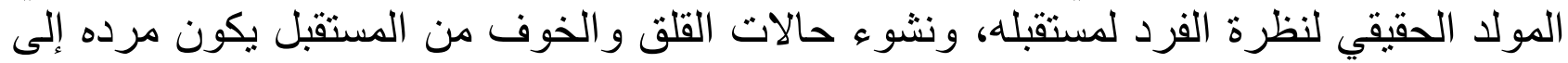

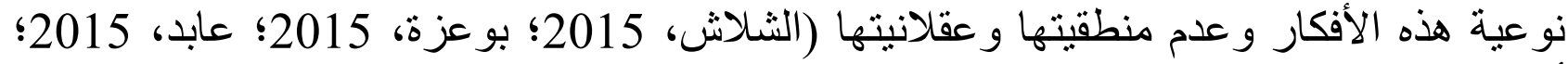
أبو فسيفس، 2015).

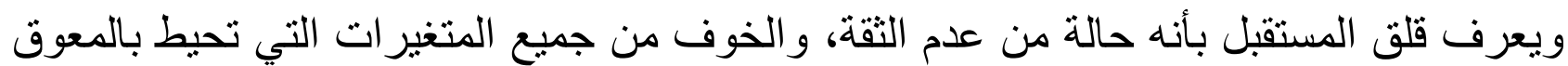

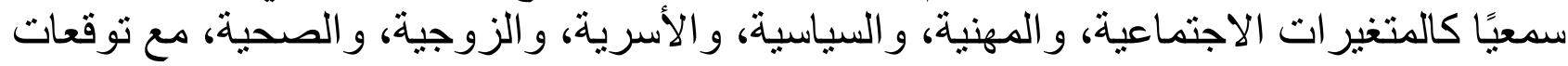

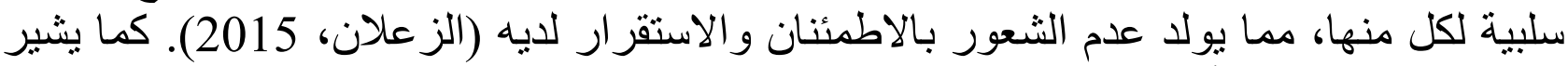

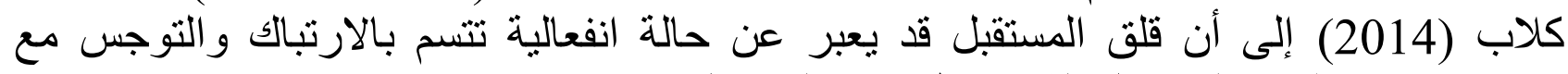
توقعات تشناؤمية من المجهول الذي الذي ينتظره في المستقبل.

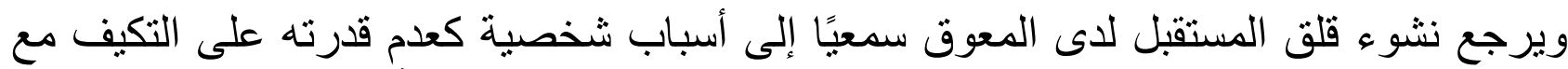

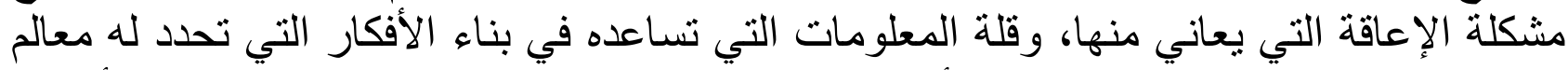

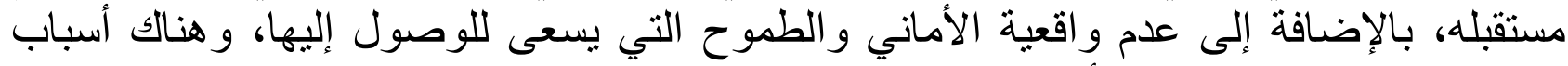

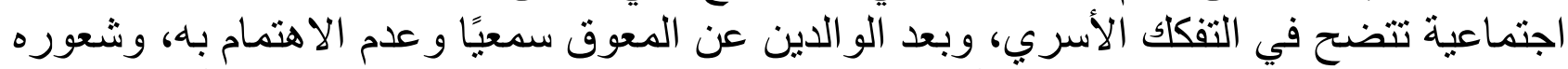

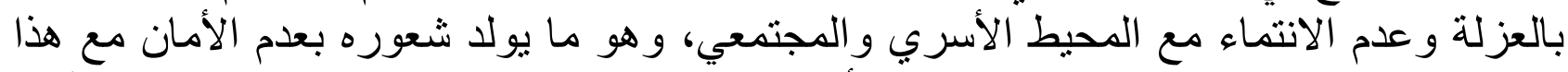

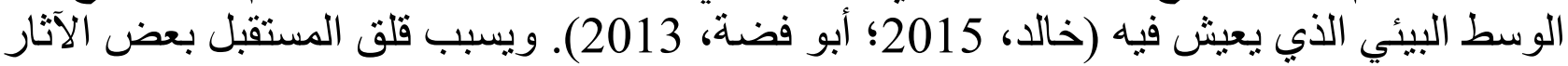

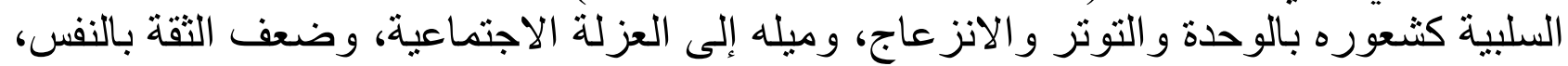

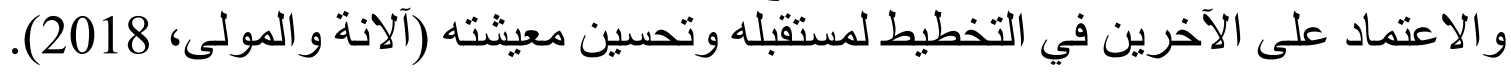

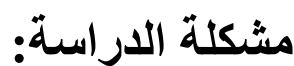

يعاني كثير من المعاقين سمعيًا من بعض المشكلات التي تعيق عملية إندماجهم الصحي مع المحيط الصيط

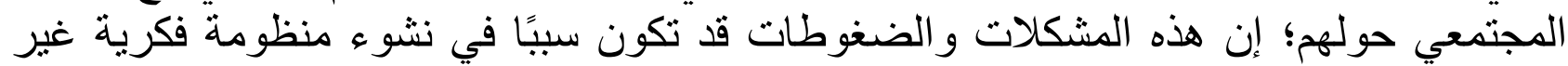
عقلانية يحاكم من خلالها المعوق سمعيًا مختلف المو اقف التي يمر بلت بها، ويضعها كمعيار لإصدار 
أحكامه و اختيار سلوكياته وبناء تصور اته حول ذاته و الآخرين، وهو ما يجعله مهددًا ليكون ضحية

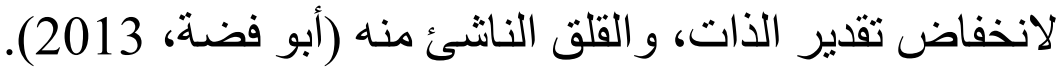

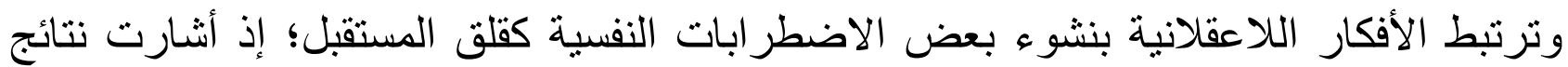

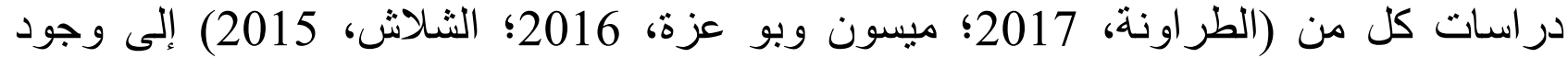

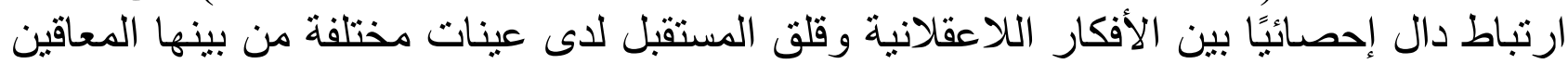

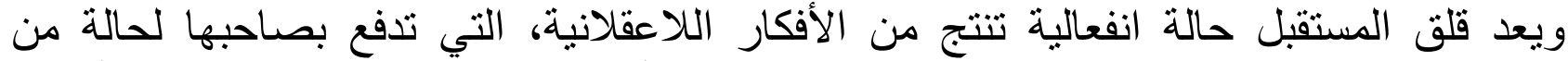

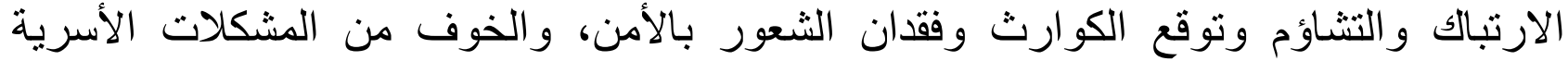

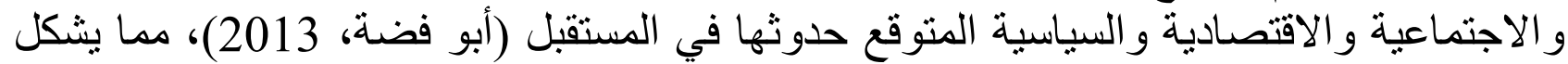

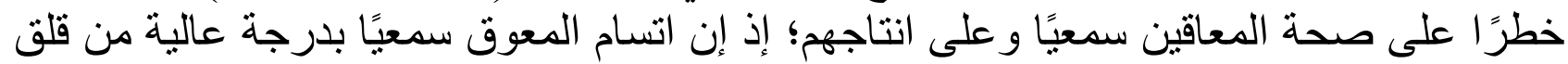

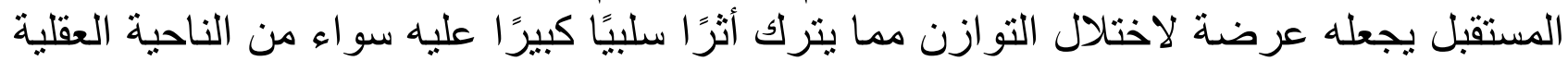

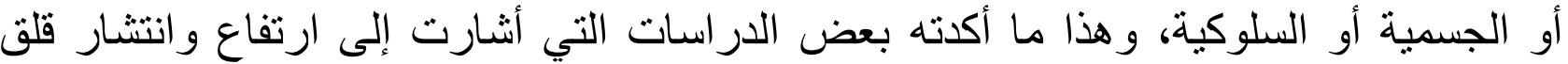

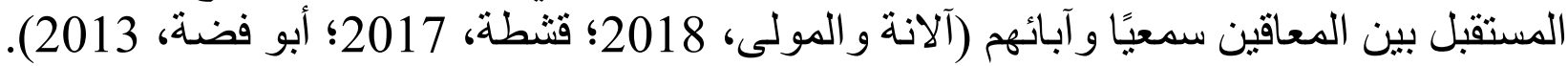

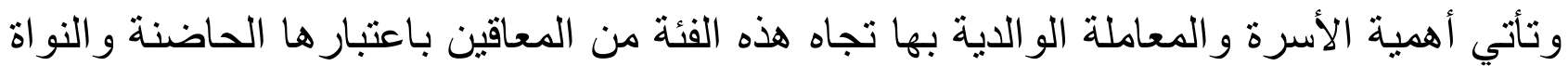

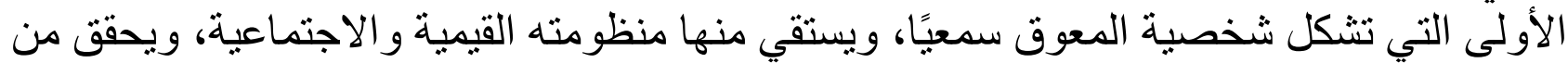

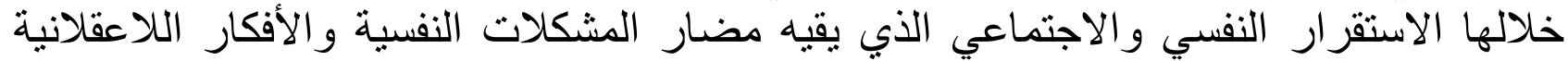

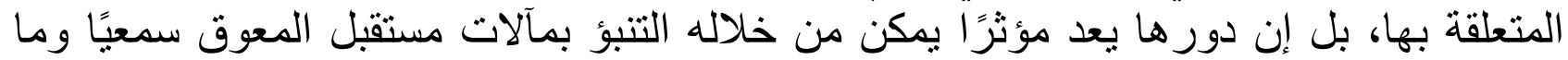

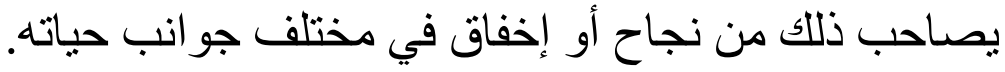

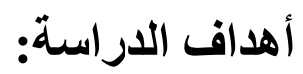

أ. تشخيص مستوى انتشار قلق المستقبل لاى طلبة الإعاقة السمعية بسلطنة عمان.

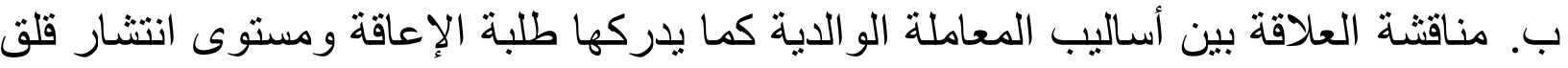
المستقبل لديهم.

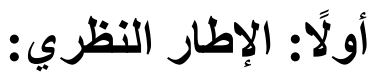

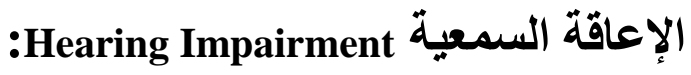

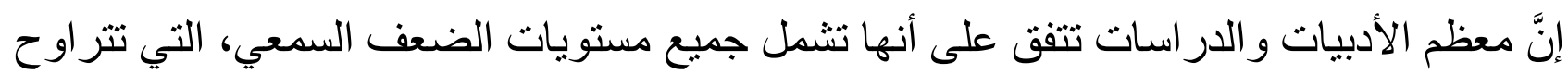

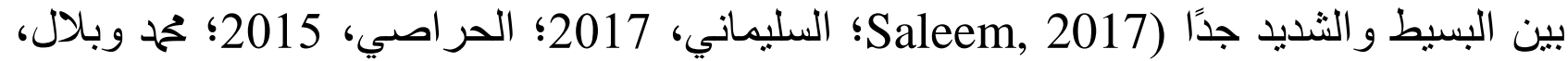
2016)، وربما تعني انحر اف في حاسة السمع يعيق القدرة على التئي التواصل السمعي اللفظي، مما يعني ضرورة تقديم الخدمات و الرعاية.

وقد حدد (بخيث، 2017؛ عوض الله، 2015؛ محمد، 2015) الإعاقة السمعية في ثلاثة أبعاد هي:

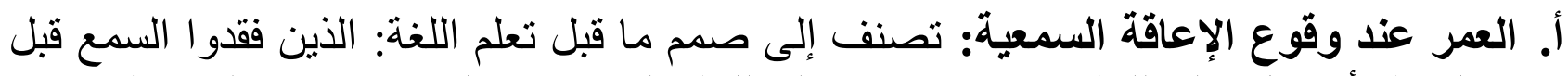

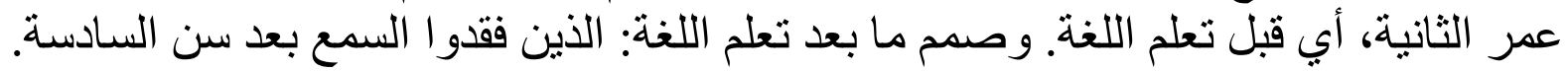

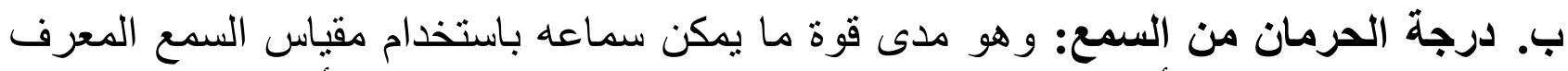

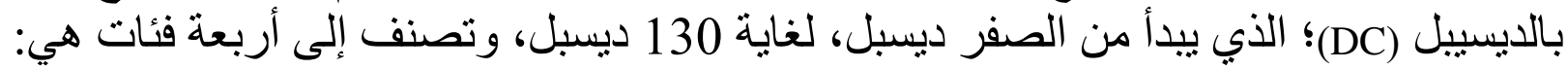


- احتياجات سمعية بسيطة: ويتر اوح فقدان السمع لهذه الفئة ما بين 20 - 40 ديسبل.

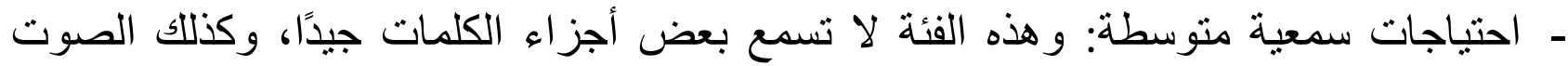

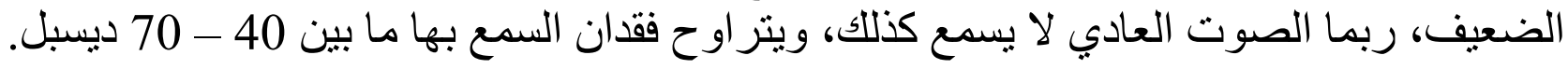
- احتياجات سمعية شديدة: ينعدم سماع الكلام، ويتر اوح فقدان السمع بها ما بين 70 - 90 - 90 ديسبل. ـ احتياجات سمعية شديدة جدًا: تعرف بالصدم التام، فقدان السمع بها إلى أكثر من 90 ديسبل.

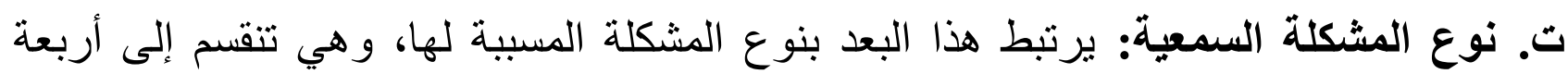
مسببات هي: توع الميكان

- عز سمعي إيصالي: ويقصد به وجود خلل في إيصال الصوت إلى العصب السمعي، - عجز سمعي عصبي حسي: وينجم عادة بسبب وجود خلل في قوقعة الأذن الداخلية.

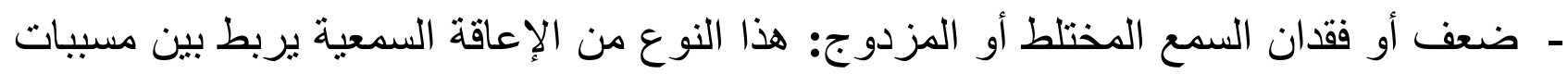
العجز في الحالتين السابقتين. ـ فقدان السمع المركزي: يأتي ذللك بسبب خلل يصيب المر اكز السمعية في الدماغ. خصائص المعاقين سمعيًا:

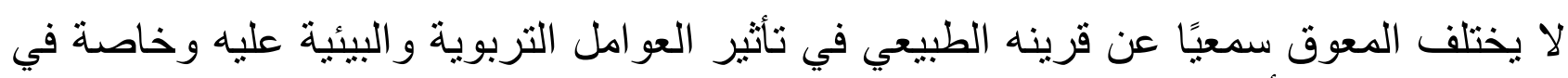

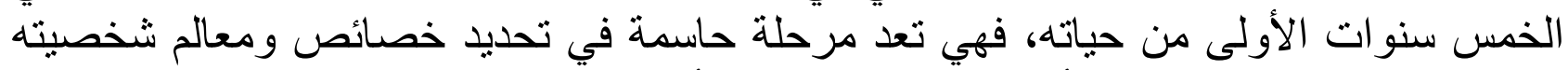

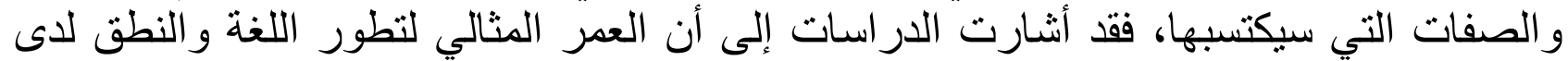

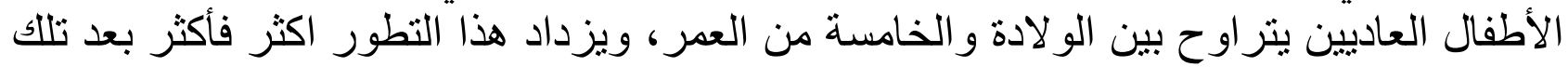

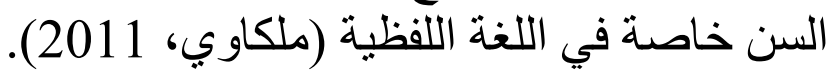

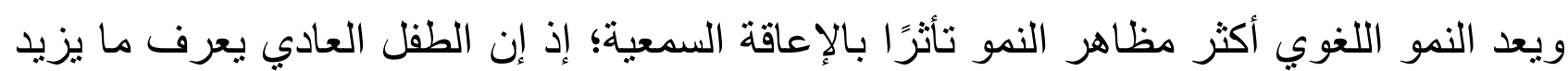

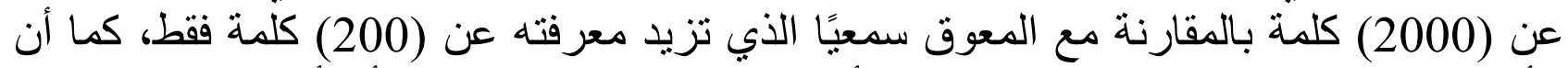

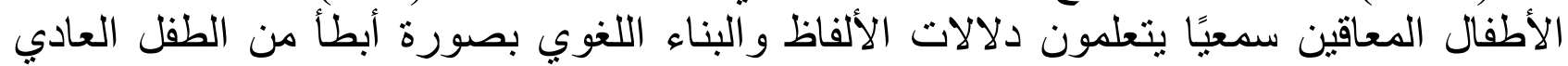

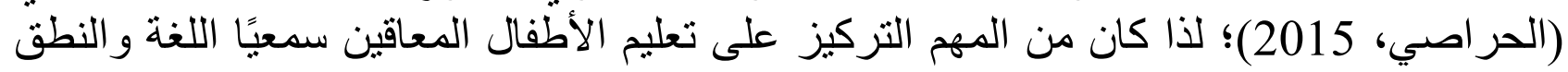

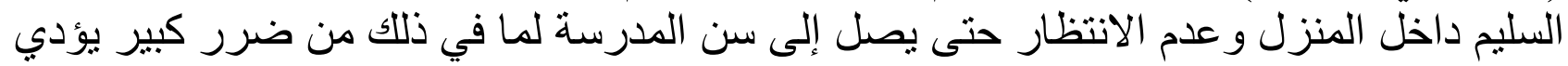
إلى تضاعف مشكلاتهم اللغوية (ملكاوي، 2011).

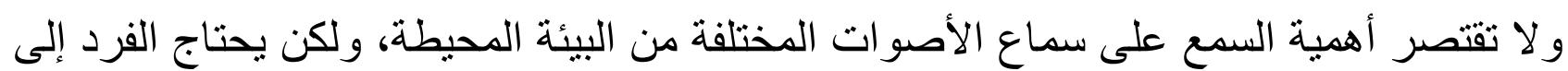

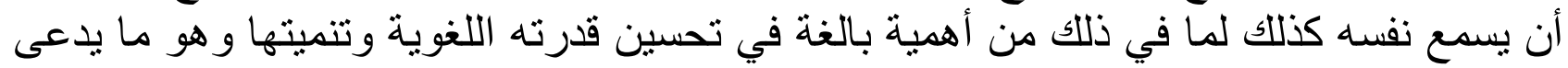

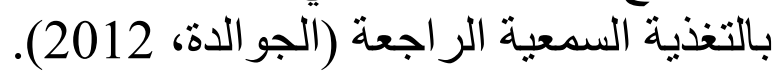

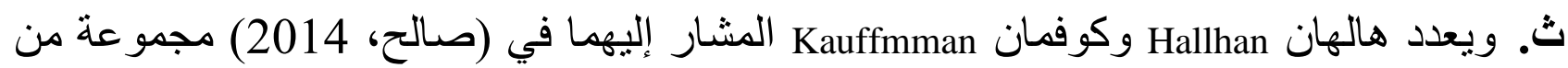

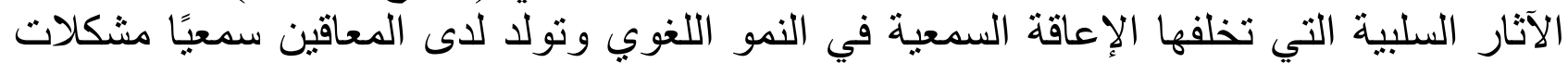

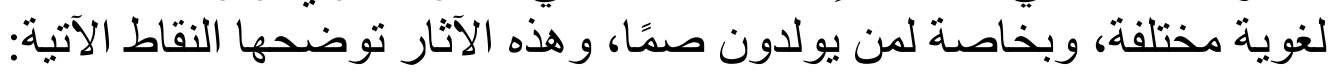
- عدم وصول أي رد فعل سمعي أو لفظي من الآخرين عندما يصدر الأصم صونًا. ـ ـليس لادى الأصم أي إمكانية لسماع المفردات من الآخرين حتى يستطيع تكر ارها وتقليد هنا. 


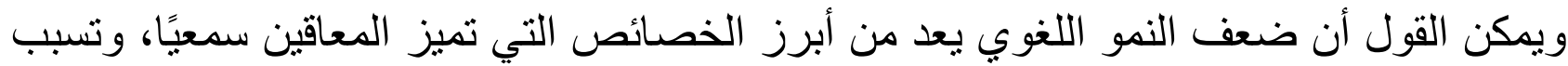

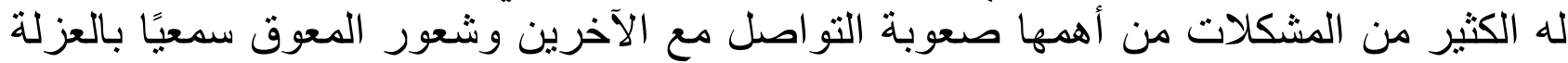

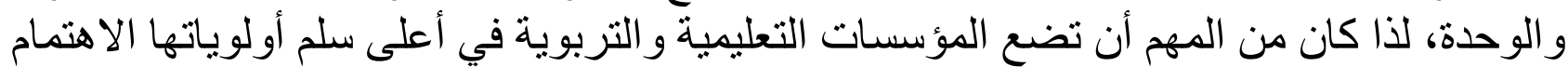
بالنمو اللغوي وتداركه في المر احل العمرية المبكرة من حياة المعوق سمعيًا؛ حتى يستطيع.

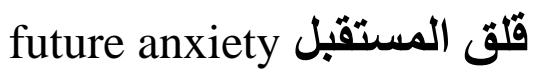

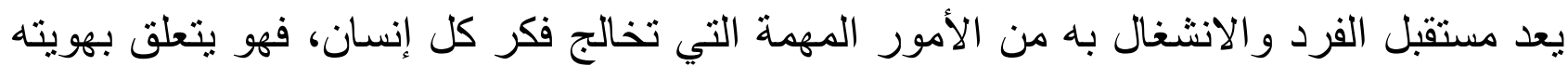
ووجوده، و الو اقع الذي يسعى للوصول إليه؛ لذا عد التفكير في المستقبل ثمرة حتمية يشترك فيه التيه

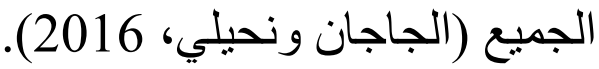

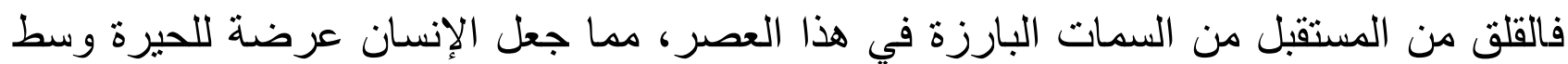

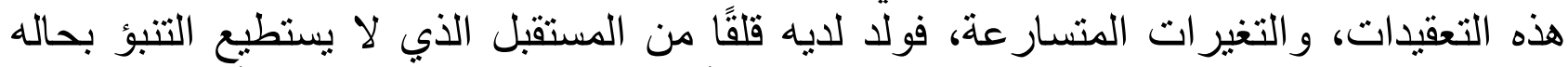

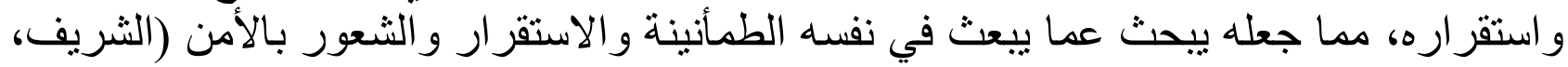

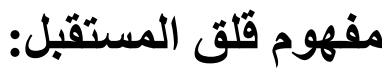

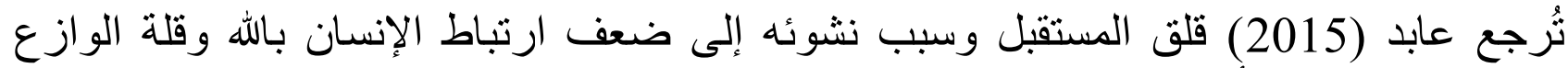

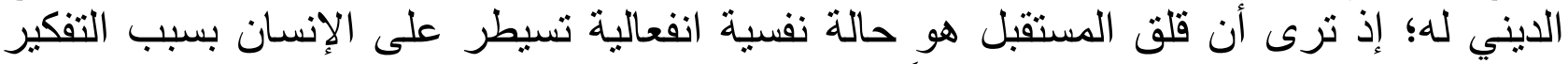

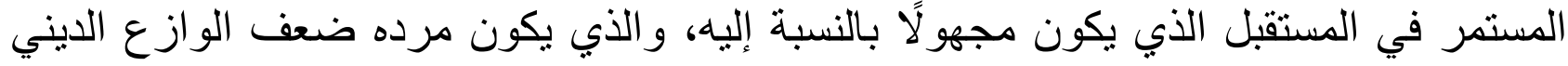
لايه و الايمان بالقضاء و القدر، مما يجعله عرضة للخون للخوف و الاضطر البه النفي النفسي المستمر.

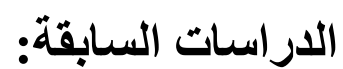

اطلع الباحث على مجمو عة و اسعة من الدر اسات السابقة، وقد راعى في اختياره للإر اسات السابقة

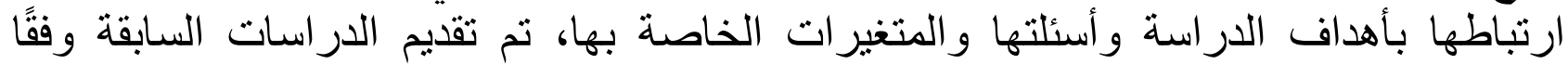
لمحورين هما: ما تتعلق بالمعاملة الوالدية وقلق المستقبل. ودراسات تتعلق بالمعوق سمعيًا وقلق التقات

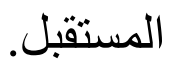

دراسات تتعلق بالمعاملة الوالدية وقلق المستقبل:

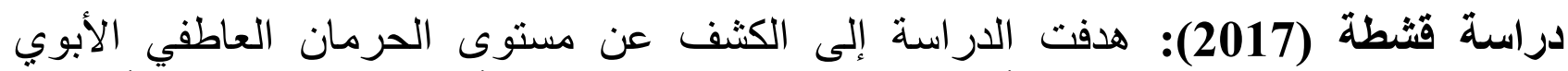

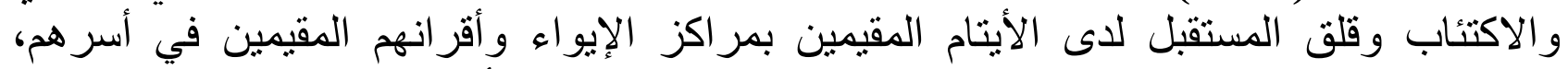

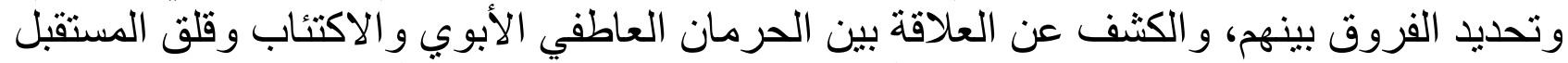

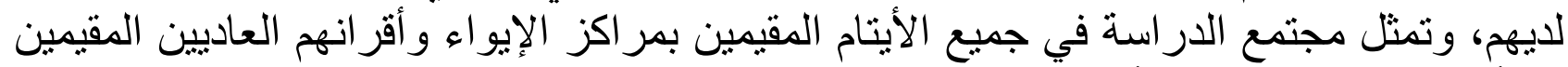

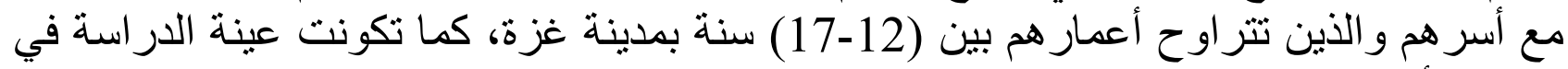

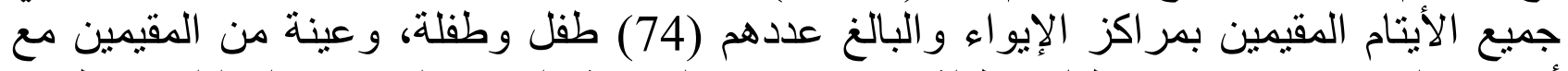

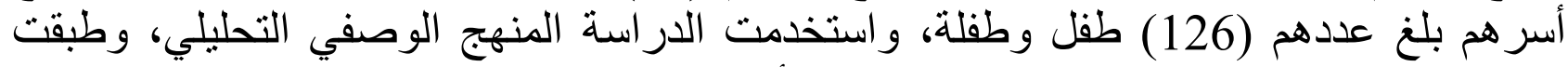

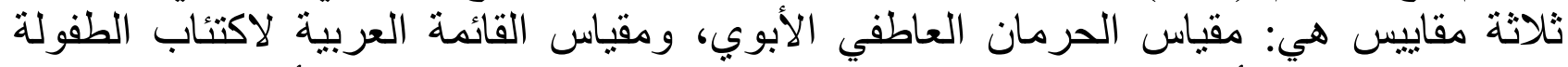

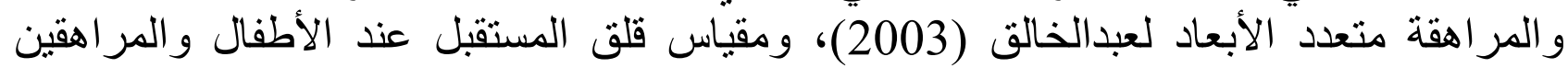
الثقير(2005)، وخلصت الدئ الدر اسة إلى نتائج منها:

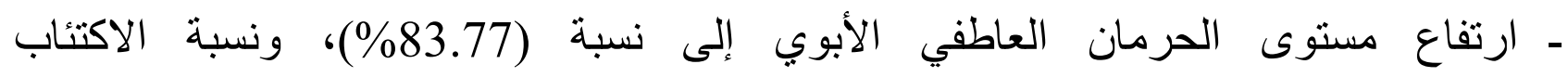




$$
\text { (61.042\%)، ونسبة قلق المستقبل (66.24\%) لدى الأيتام. }
$$

- ـ وجود علافة ارتباطية بين الحرمان العاطفي الأبوي وقلق المستقبل، في المجالات وفي الدرجة الكلية لقلق المستقبل.

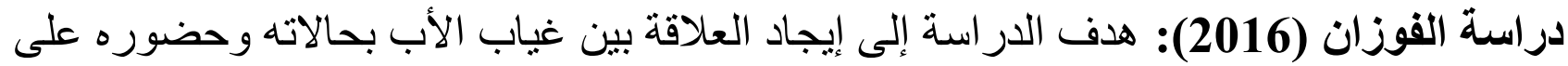

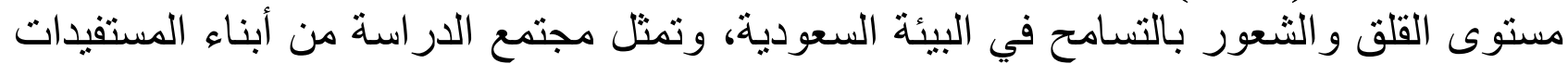

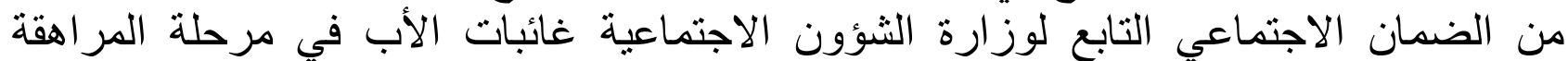

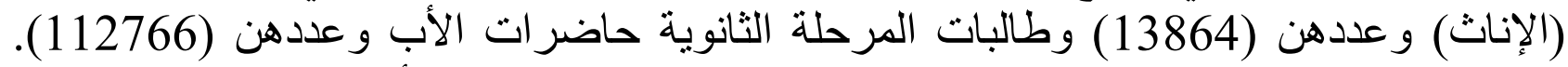

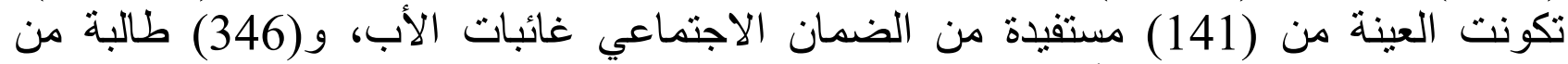

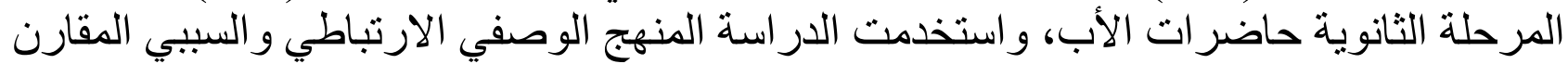

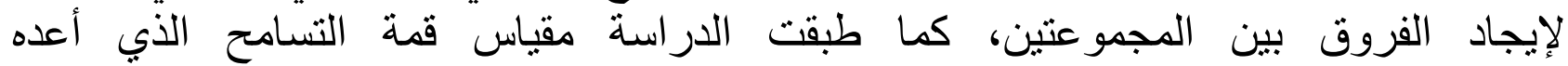

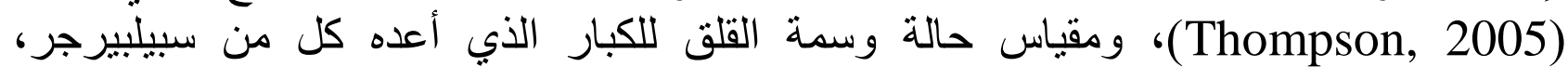
جورستش، لوشين(1893)، وخلصت الدر اسة إلى مجمو عة من النتائج منها:

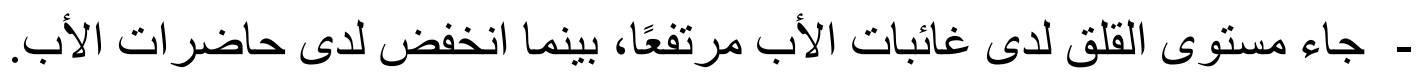

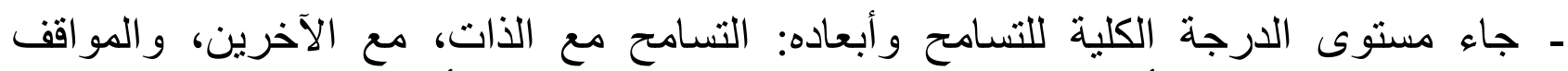

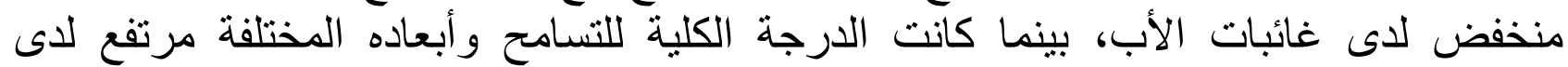

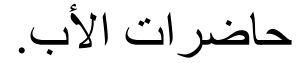

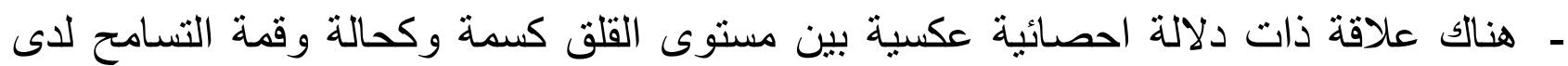

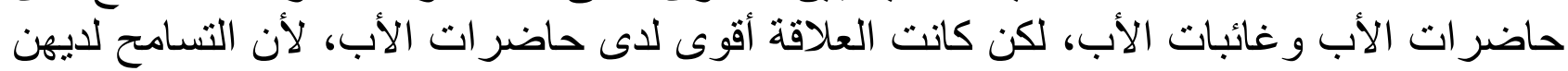
مرتفع مما يقلل القلق. دراسات تتعلق بالمعوق سمعيًا وقلق المستقبل:

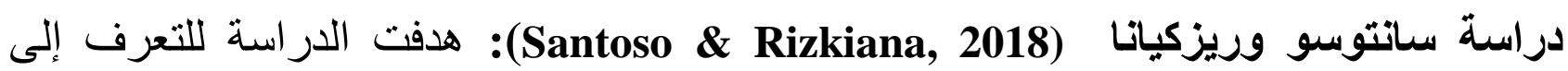

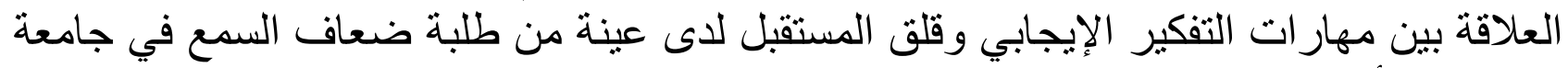

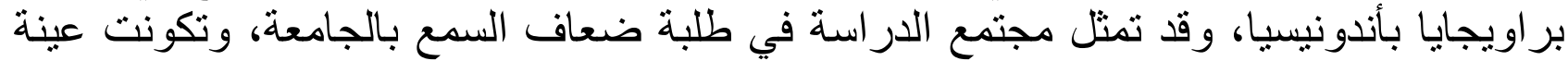

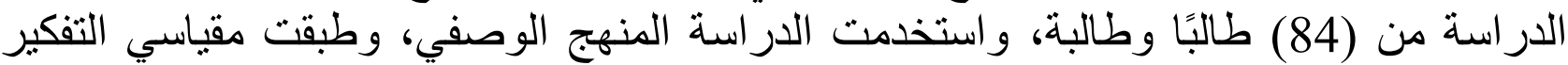

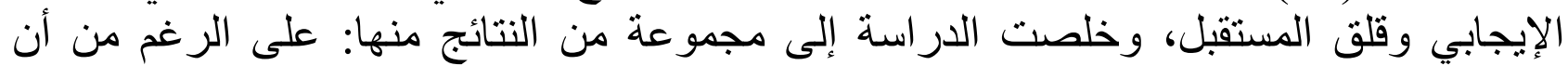

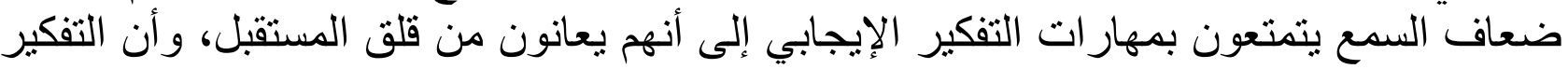
الإيجابي لم يساعد بشكل كبير في التقليل من قلق المستقبل ولكنه يساعد في التحكم في مستوى التئ القلق.

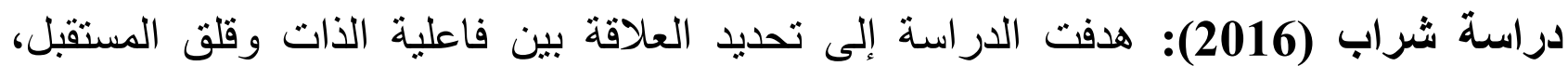

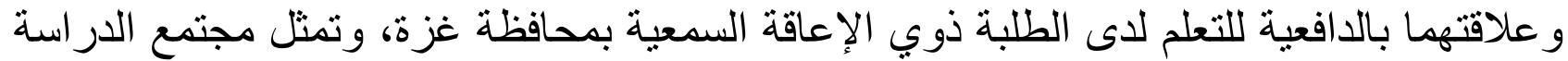

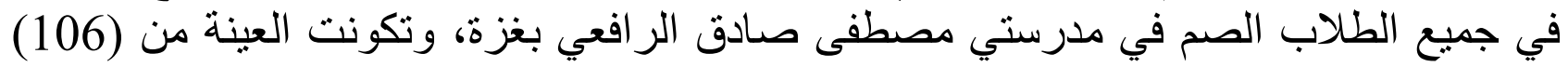

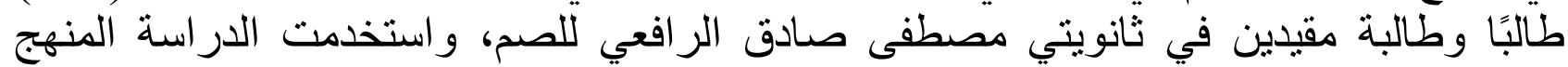

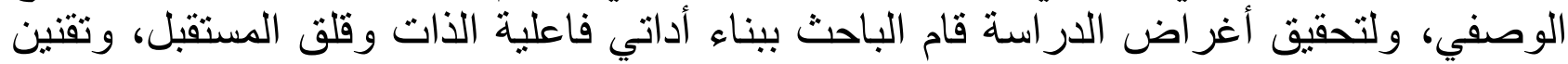

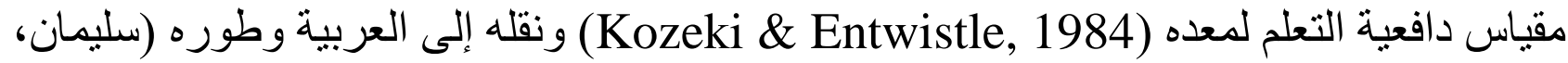
1989)، وخلصت الدر اسة إلى مجمو عة من النتائج منها: 


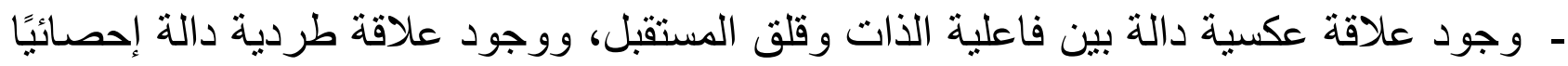
بين فاعلية الذات و الدافعية للتعلم، و علاقة عكسية ضعيفة دالة إحصائيًا بين قلق المستقبل و الدافعية

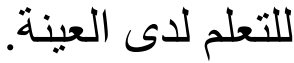
- وجود فروق ذات دلالة إحصائية بين متوسطي درجات الذكور والإناث على مقياس قلق الإنق المستقبل، ولصالح الطلبة ذوب ذات دلة الإعاقة السمعية الذكور.

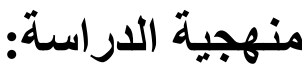

تقع الدر اسة الحالية ضمن المنهج الوصفي، الذي يدرس ظاهرة أو حدث أو قضية موجودة حاليًا،

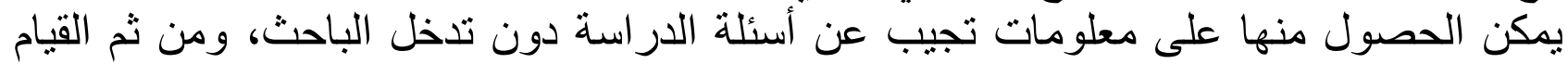

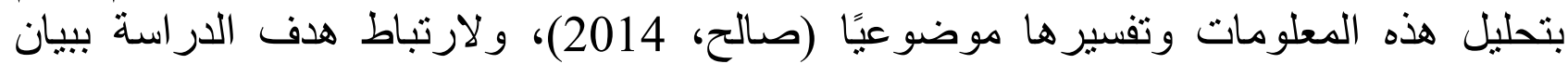

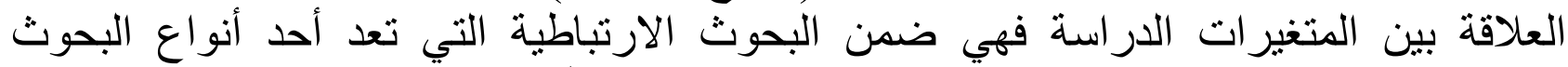

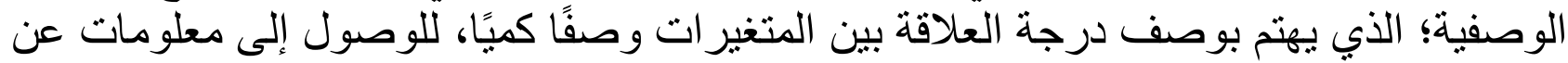

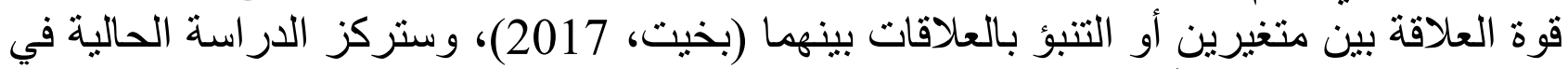

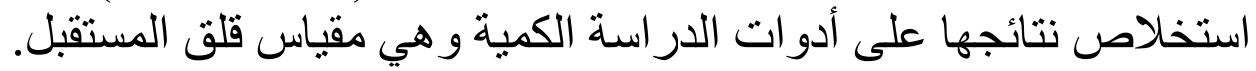

\section{مجتمع وعينة الدراسة:}

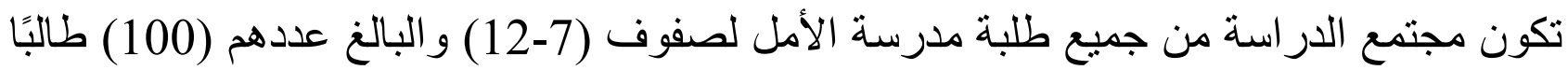

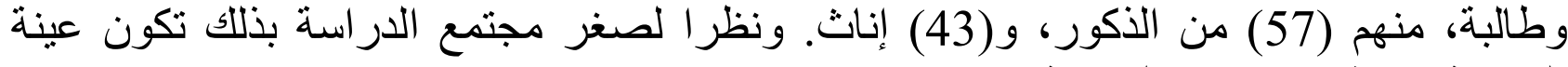
الدر اسة هي ذاتها مجتمع الدر اسة.

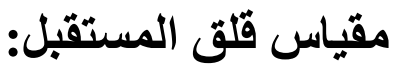
بناء المقياس:

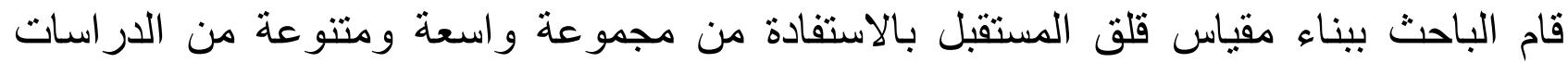

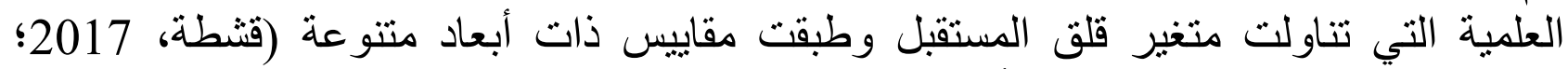

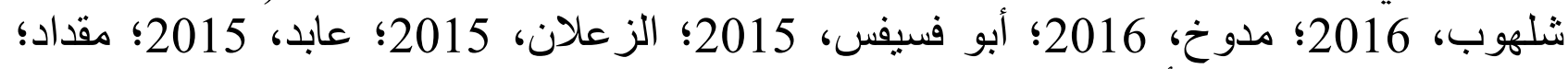

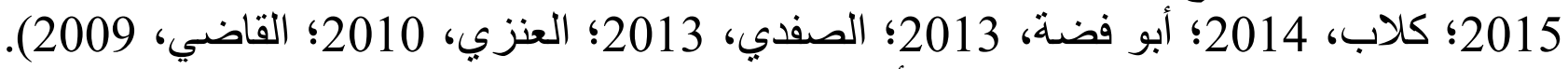

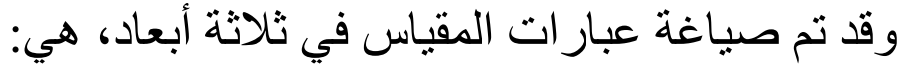

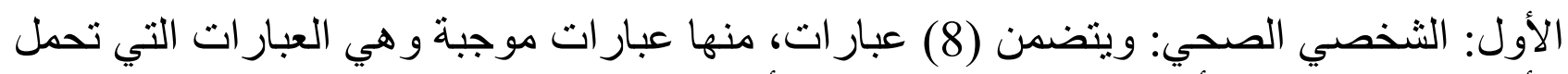

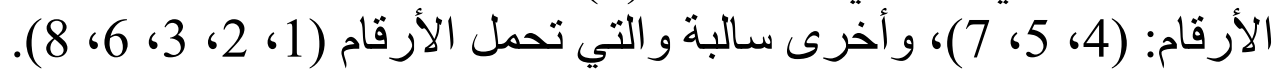

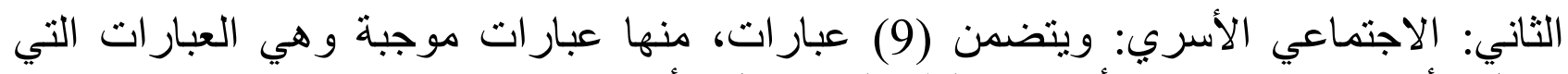

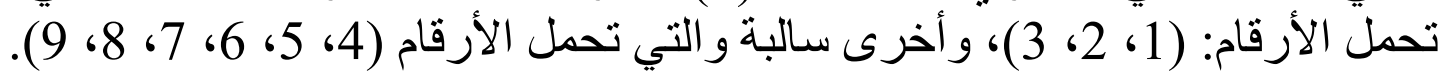

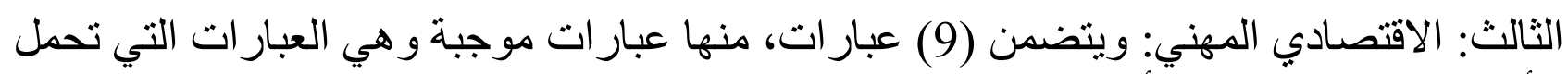

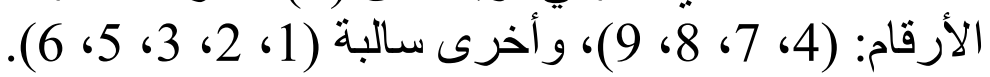

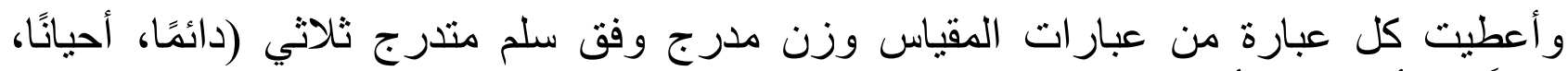

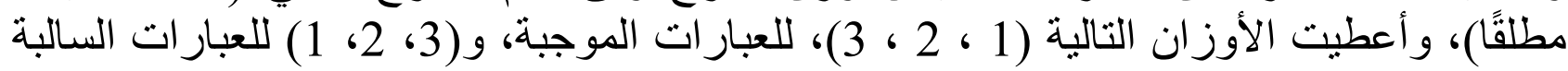


لتحديد مستوى قلق المستقبل لدى العينة (طلبة الإعاقة السمعية)، وبذلك تتحصر درجات أفراد

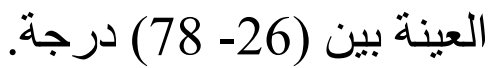

تصحيح المقياس:

قياس الصدق الظاهري لمقياس قلث المستقبل:

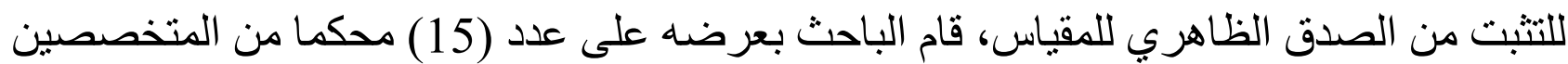

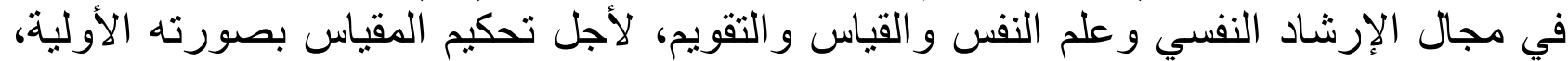

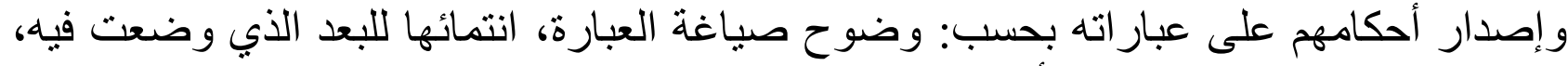
تعديل العبار ات، إضـافة عبار ات أخرى.

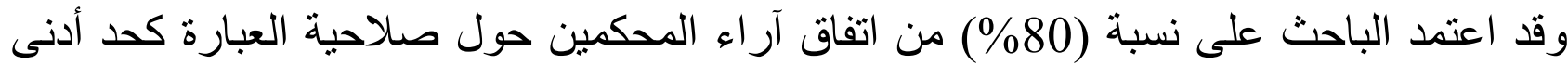

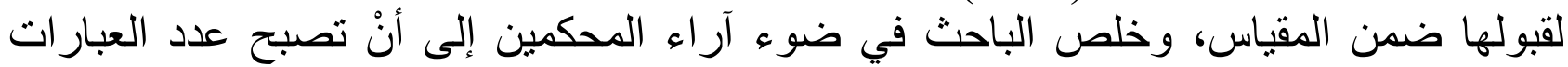

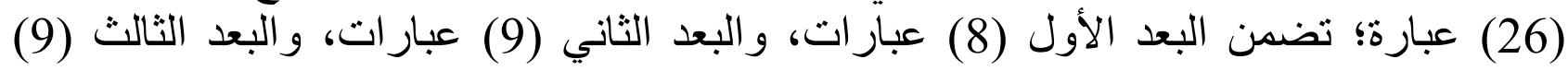

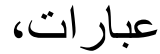

\section{صدق الاتساق الاخلي لمقياس قلق المستقبل:}

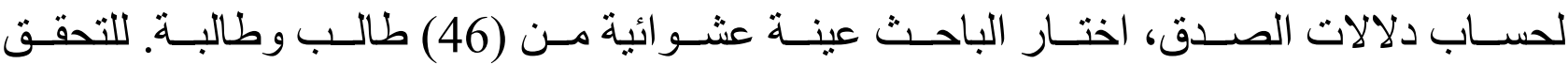

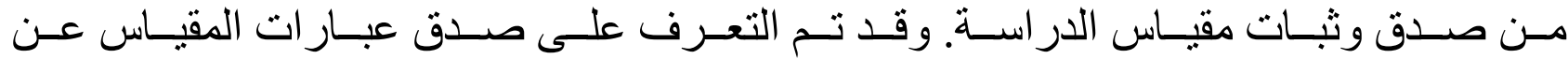

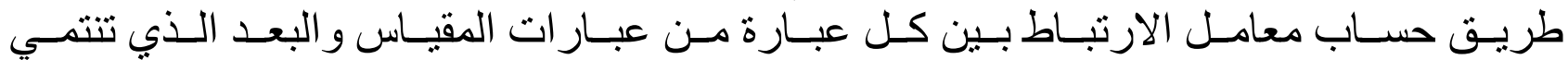

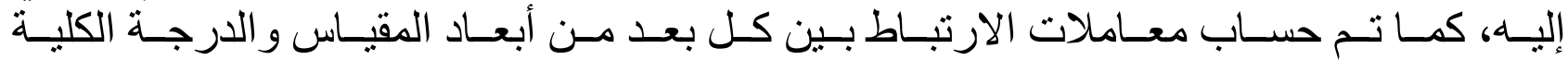

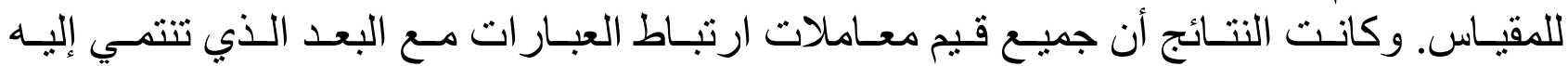

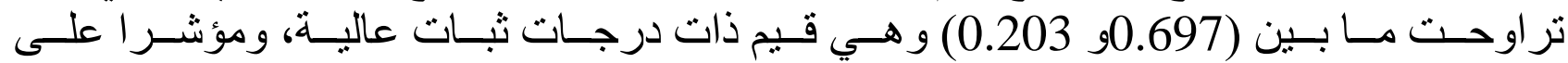

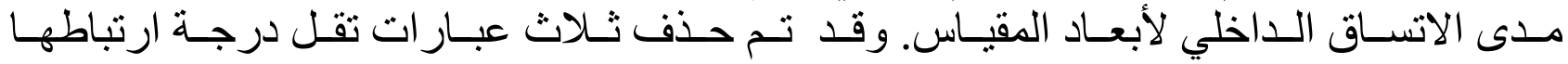

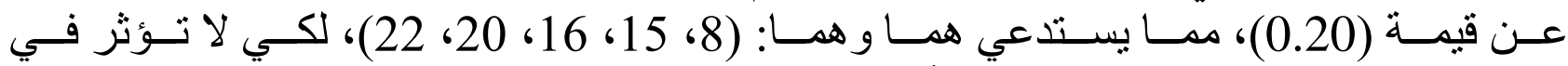

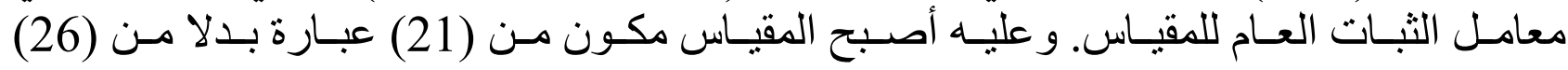

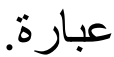

ثبات المقياس:

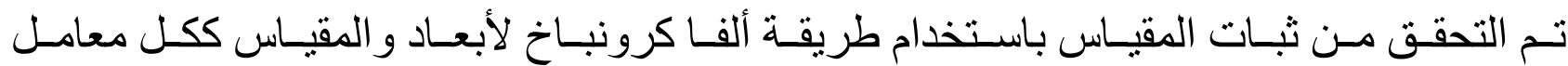

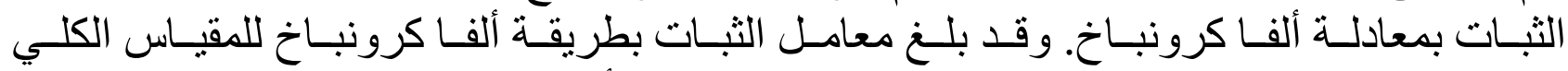

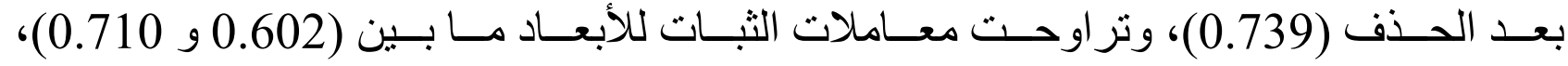

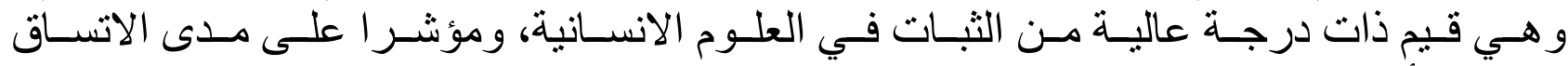
الداخلّي لأبعاد المقياس. المعالجة الإحصائية : الإنية

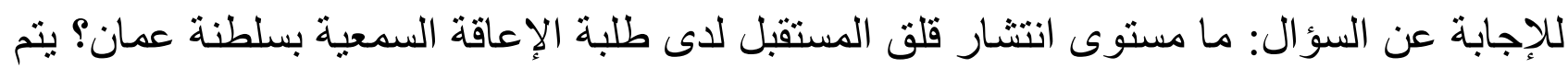
استخر اج المتوسطات الحسابية و الانحر افات المعيارية لاستجابة المات الفر اد العينة. و عن وجود علاقة بين أساليب المعاملة الو الدية كما يدركها طلبة الإعاقة السمعية بمستوى انتشار قلق المستقبل لديهج؟ تم استخدام معامل ارتباط بيرسون البة (Pearson Correlation Coefficient). 


\section{نتائج الاراسة}

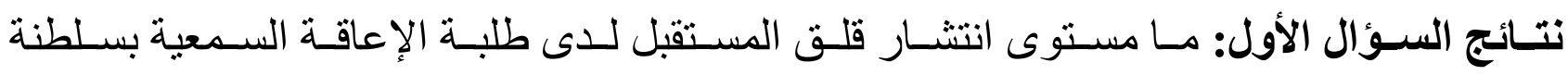
عمان?

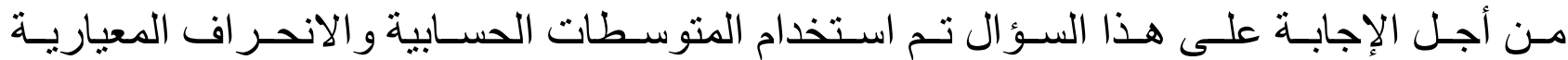

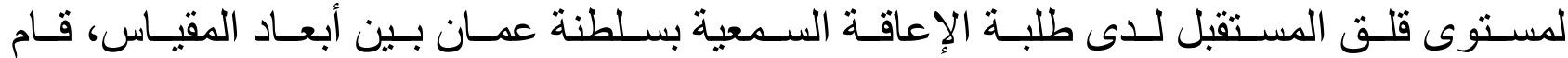

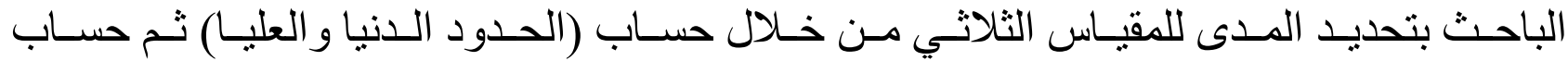

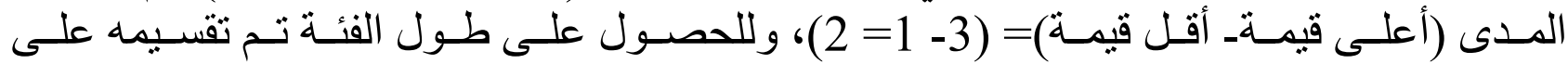

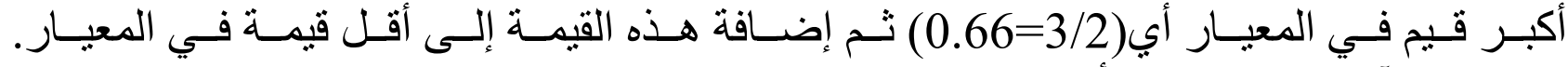
والجدول الآتي يبين مجمل الأبعاد:

جدول (1) مستوى قلق المستقبل لدى طلبة الإعاقة السمعية

\begin{tabular}{|c|c|c|c|c|c|}
\hline المستوى & المرتبة & الانحرا & الحستبي & أبعاد مقياس & b \\
\hline منخفض & 1 & 0.31 & 1.63 & الشخصي الصحي & 1 \\
\hline منخفض & 2 & 0.32 & 1.60 & الاجتماعي الاسري & 2 \\
\hline منخفض & 3 & 0.34 & 1.57 & الاقتصادي المهني & 3 \\
\hline منخفض & & 0.26 & 1.60 & المجموع الكلي & \\
\hline
\end{tabular}

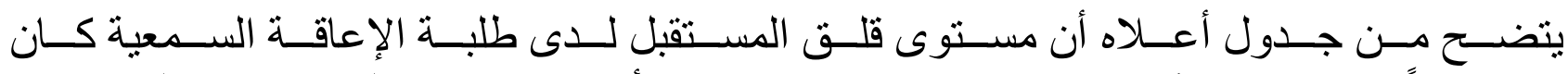

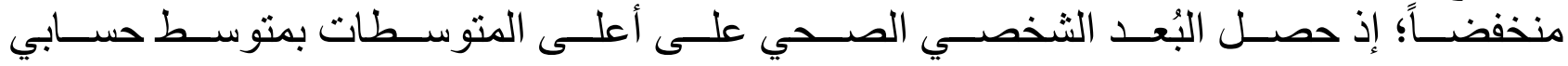

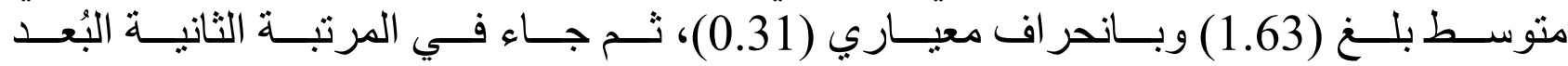

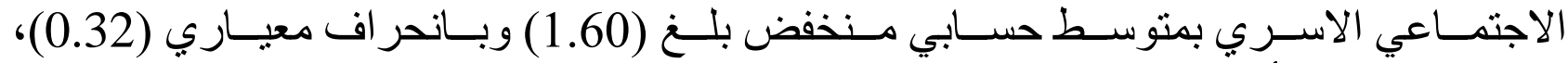

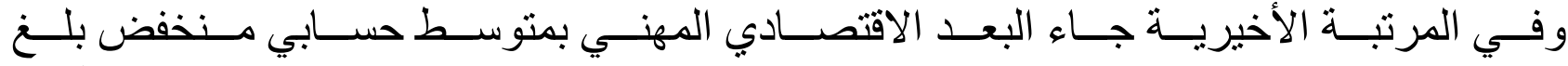

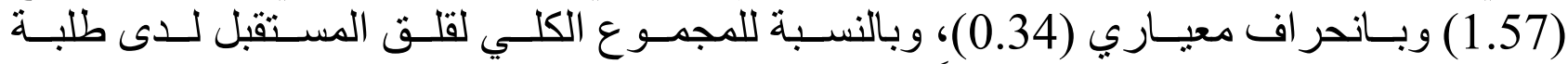

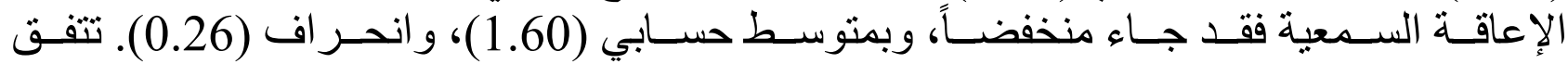

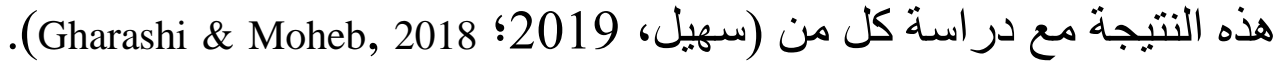

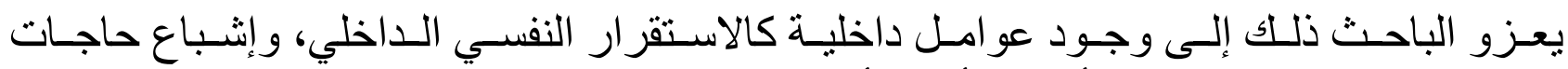

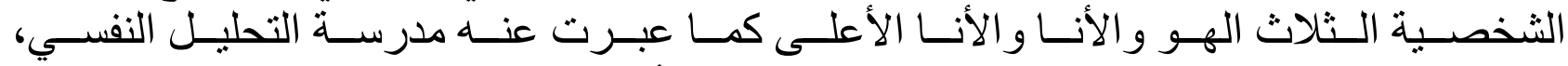

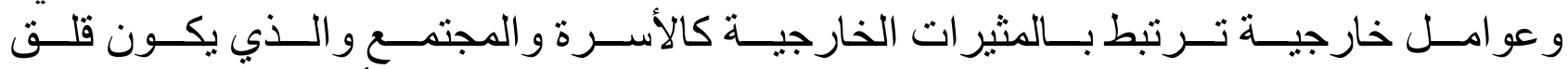

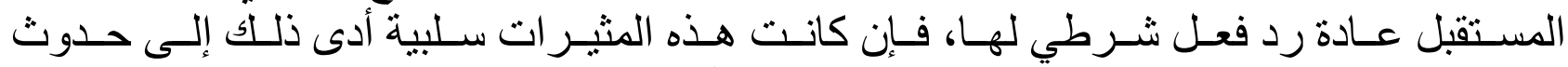

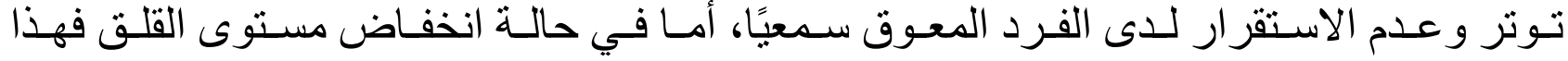
يدل على إيجابية هذه المثير ات كما تر اها المدرسة السلوكية.

النتائج حسب أبعاد عبارات المقياس: 


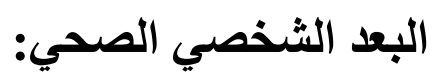

جدول (2) تقدير ات العينة لعبار ات البعد الشخصي الصحي مرتبة تنازليا حسب المتوسطات الحسابية

\begin{tabular}{|c|c|c|c|c|c|}
\hline 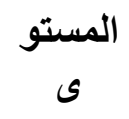 & 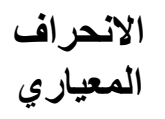 & المتسابي & عبارات البعد الشخصي الصحي & الرقم & الرتبة \\
\hline متوسط & 0.69 & 1.82 & ألنتقرت بصعوبة في النوم كلما في فكرت في & 14 & 1 \\
\hline 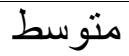 & 0.70 & 1.80 & أرى أن اعاقتي لن تكون عائقًا أمام تحقيق أهدافي. & 17 & 2 \\
\hline 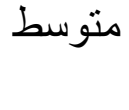 & 0.70 & 1.72 & الأجيام والسنوبة أكبر في تحقيق الطوحات كلما مرت & 4 & 3 \\
\hline منخف & 0.73 & 1.65 & 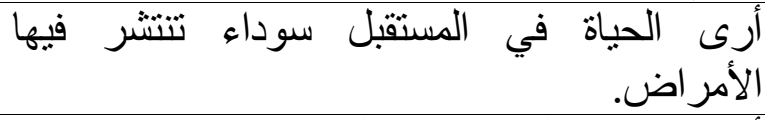 & 7 & 4 \\
\hline 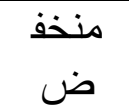 & 0.56 & 1.54 & أخشى من الفنشل في المستقبل. & 1 & 5 \\
\hline 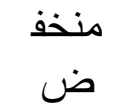 & 0.59 & 1.52 & أشُعر بأنني سأكون شخصية مهمة في وطني. & 12 & 6 \\
\hline منخف & 0.60 & 1.42 & أثق أن قدراتي الصحية ستتحسن في المستقبل. & 9 & 7 \\
\hline منذف & 0.31 & 1.63 & المستوى العام & & \\
\hline
\end{tabular}

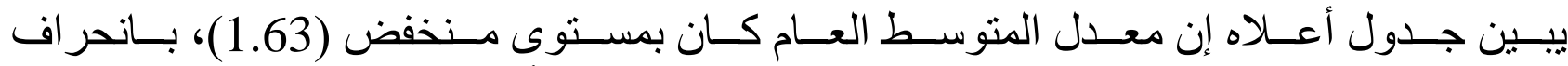

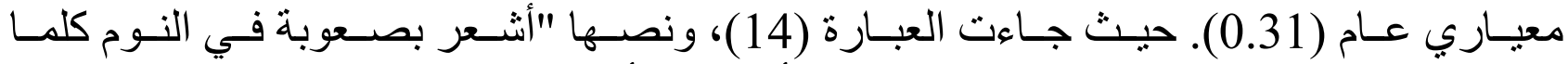

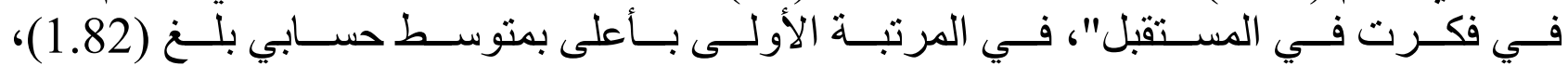

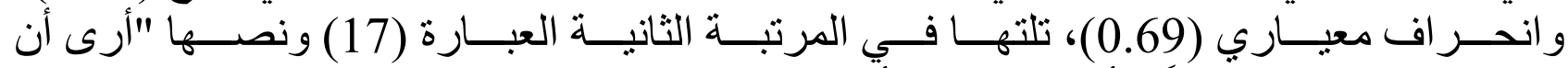

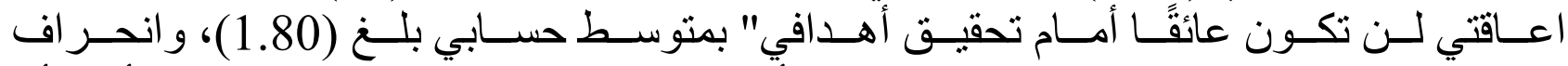

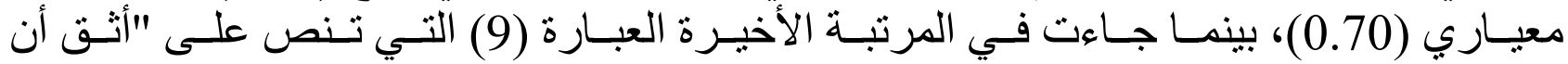

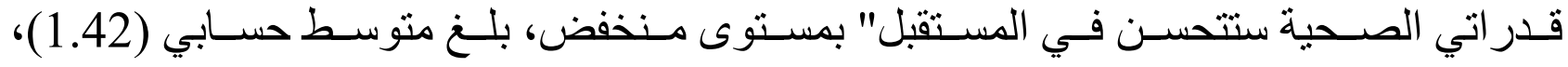
وانحر اف معياري (0.60).

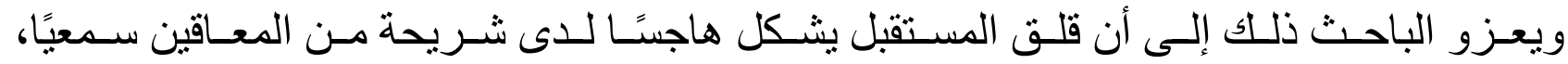

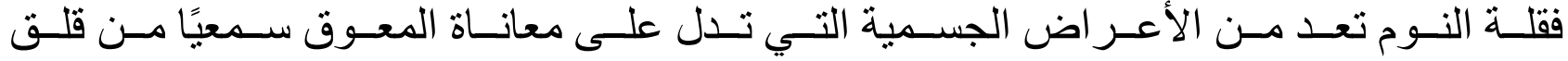

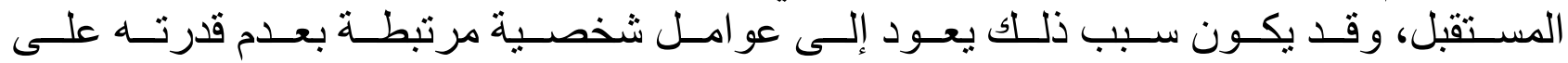

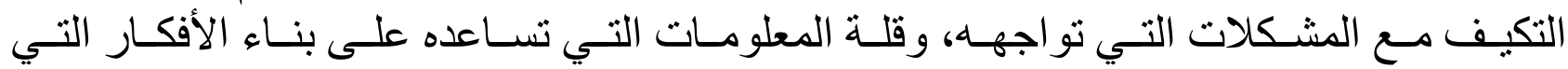

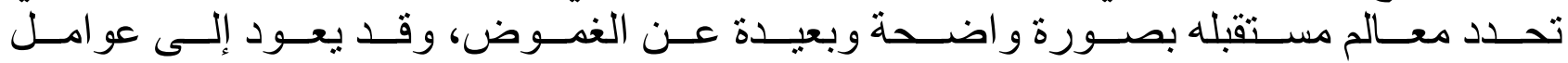

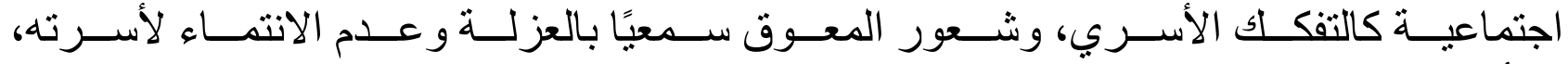

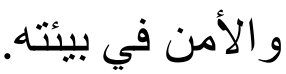


البعد الاجتماعي الأسري:

جدول (3) تقدير ات العينة لعبار ات البعد الاجتماعي الأسري مرتبة تنازليا حسب المتوسطات الحسابية

\begin{tabular}{|c|c|c|c|c|c|}
\hline 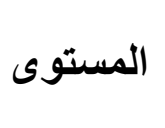 & 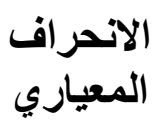 & المستوسط & عبارات البعد الاجتماعي الأسري & 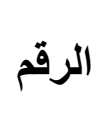 & 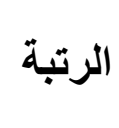 \\
\hline متوسط & 0.73 & 1.81 & أعستقبل أنه من الصعب إيجاد شريك الحياة في & 15 & 1 \\
\hline منوسط & 0.63 & 1.79 & أقلق من الثعور بالعزلة و الوحدة في المستقبل. & 20 & 2 \\
\hline متوسط & 0.82 & 1.73 & تراودني فكرة إنجاب أطفال معاقين بعد الزوواج. & 13 & 3 \\
\hline متوسط & 0.67 & 1.67 & أثشعر بعدم الاطمئنان كلما فكرت في الزواج. & 10 & 4 \\
\hline 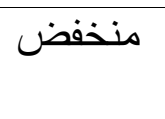 & 0.58 & 1.47 & أرستقبل. أن المجتمع سيتقبلني كفرد فاعل في & 5 & 5 \\
\hline منخفض & 0.59 & 1.38 & الآخرين. بالسعادة عند نشوء علاقات جديدة مع & 2 & 6 \\
\hline منخفض & 0.61 & 1.36 & أتفاءل بالنجاح في حياتي الزوجية مستقبلًا. & 8 & 7 \\
\hline منخفض & 0.32 & 1.60 & المستوى العام & & \\
\hline
\end{tabular}

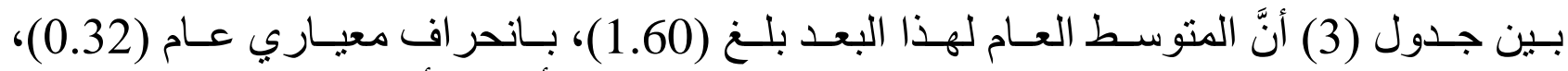

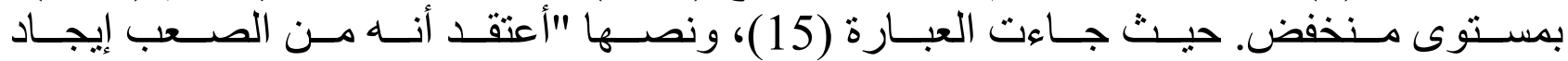

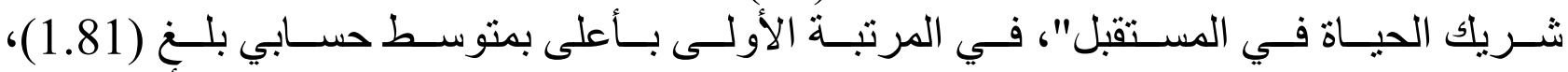

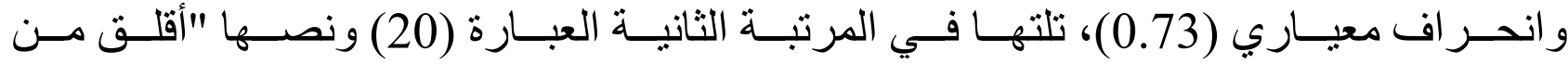

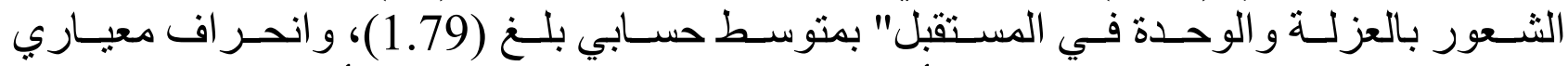

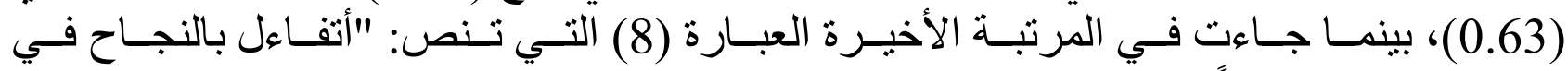

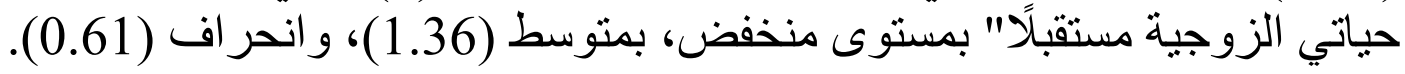

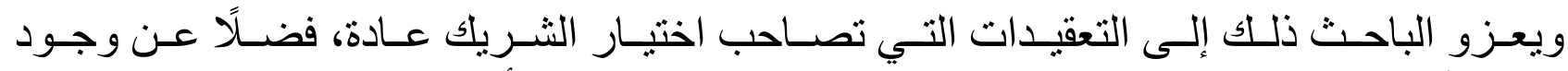

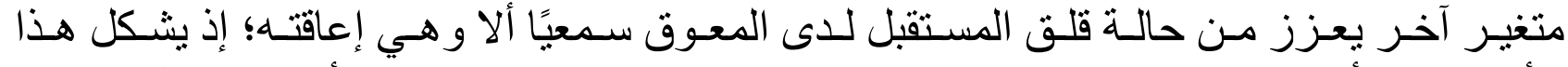

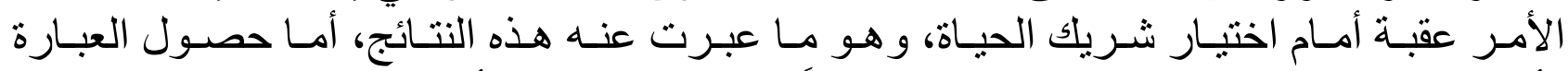

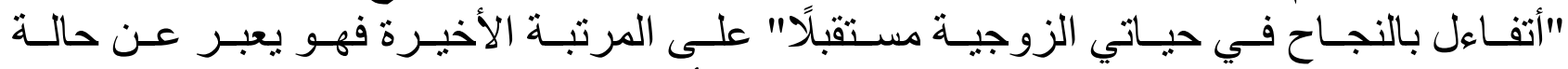

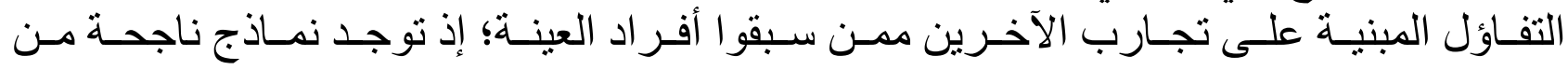
ذوي الإعاقة السمعية حققت نجاحًا في حياتهم البعد الاقتصادي المهني:

جدول (4) تقدير ات العينة لعبار ات البعد الاقتصادي المهنية مرتبة تنازليا حسب المتوسطات

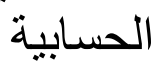




\begin{tabular}{|c|c|c|c|c|c|}
\hline 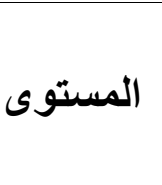 & الانحرا & المستوسط & عيا. ات البعد الاقتهادي الم من & 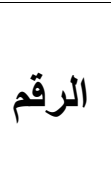 & 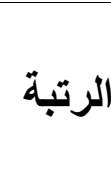 \\
\hline متوسط & 0.67 & 1.92 & أثشعر بالخوف والقلق من ارتفاع الأسعار وغلاء & 3 & 1 \\
\hline متوسط & 0.62 & 1.91 & صعب أرى أن الحصول على أي عمل في المستقبل & 6 & 2 \\
\hline منخفض & 0.61 & 1.51 & أخشى من الفشل في حياتي العملية في المستقبل. & 16 & 3 \\
\hline منخفض & 0.56 & 1.48 & أجد أن المجتمع سيساندني للحصول على مهنة & 18 & 4 \\
\hline منخفض & 0.58 & 1.46 & أشتعر أن الأوضاع الاقتصادية ستتحسن في & 19 & 5 \\
\hline منخفض & 0.51 & 1.39 & أشعر بالتفاؤل لحصولي على المهنة التي أحب في & 11 & 6 \\
\hline منخفض & 0.53 & 1.38 & أثق بقدرتي على تأمين المسكن و الحياة الكريمة في & 21 & 7 \\
\hline منخفض & 0.34 & 1.57 & المستوى العام & & \\
\hline
\end{tabular}

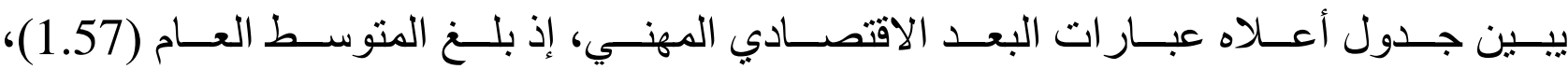

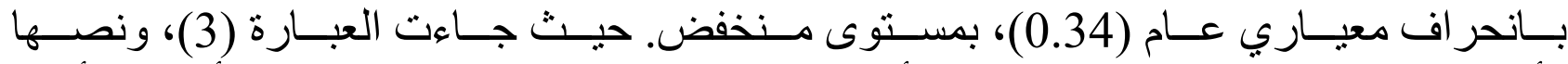

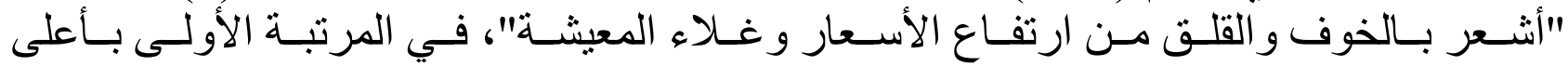

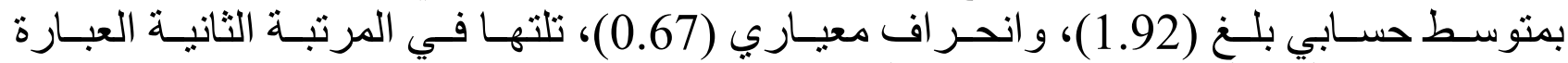

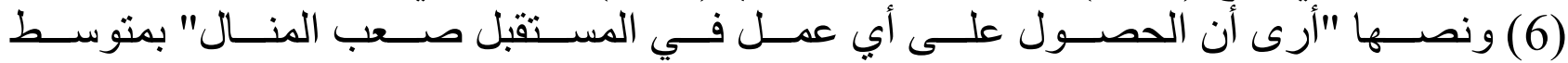

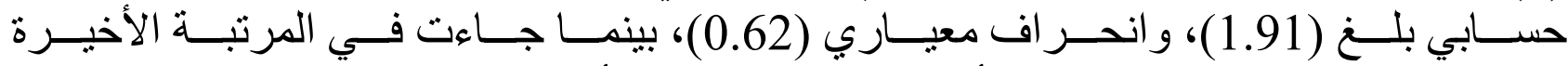

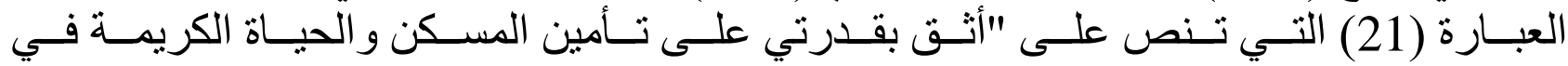
المستقبل" بمستوى منخفض، بلغ متوسط حسابي (1.38)، و انحر اف معياري (0.53).

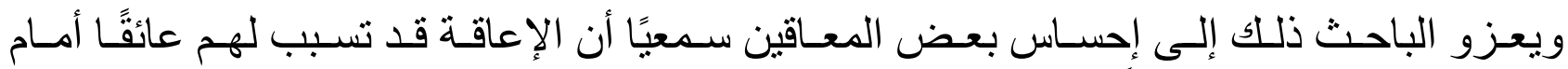

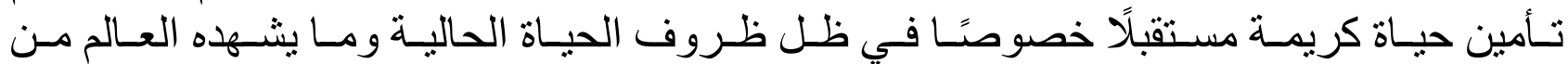

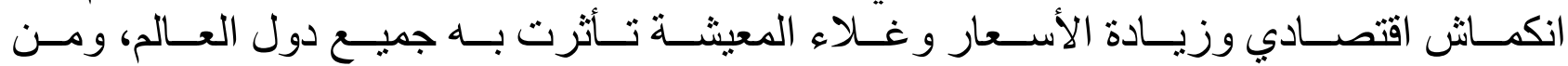

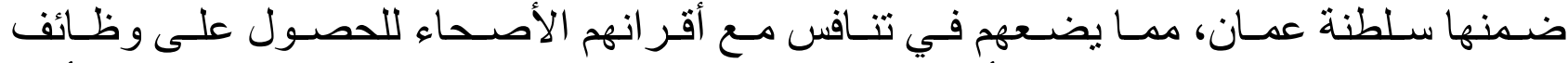

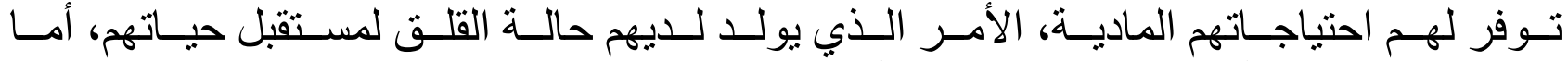

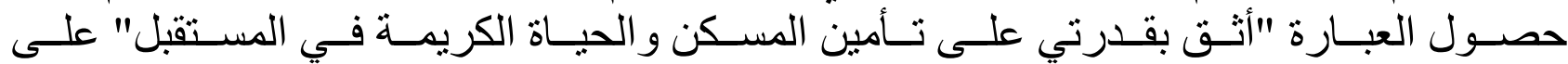

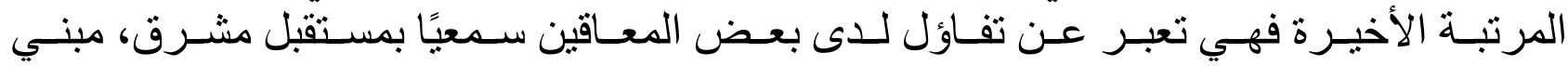

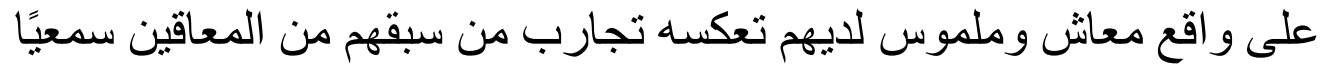

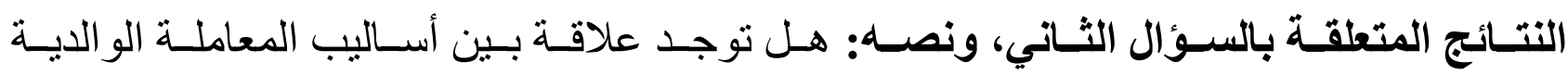

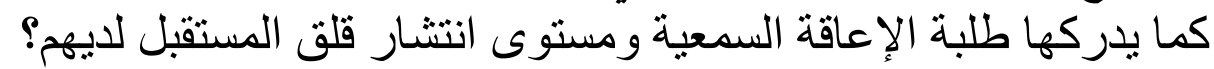
من أجل الإجابة على السؤال تم استخدام معامل ارتباط بيرسون (Pearson). جدول (5) معامل ارتباط بيرسون بين مستوى أبعاد أساليب المعاملة الوالدية و أبعاد قلق المستقبل 


\begin{tabular}{|c|c|c|c|c|c|c|c|c|}
\hline \multicolumn{8}{|c|}{ أساليب المعاملة الوالاية } & \multirow{6}{*}{ قُلق المستقبل مقياس } \\
\hline \multicolumn{4}{|c|}{ الأم } & \multicolumn{4}{|c|}{ الأب } & \\
\hline أسلوب & أسلوب & أسلوب & أسلوب & أسلوب & أسلوب & أسلوب & أسلوب & \\
\hline التشجيع & التسامح & التقبل & المساو اة & التشجيع & التسامح & التقبل & المساو اة & \\
\hline مقابل & مقابل & مقابل & مقابل & مقابل & مقابل & مقابل & مقابل & \\
\hline التتبيط & التشدد & الرفض & التفرقة & التتبيط & التشدد & الرفض & التفرقة & \\
\hline-08 & ר? & 16 & 05 & 00 & $25 *$ & 08 & 15 & الشخصي \\
\hline .00 & .02 & .10 & & . & . & .00 & .15 & الصحي \\
\hline .44 & .80 & .12 & 63 & .37 & .01 & .43 & .15 & ارتباط بيرسون \\
\hline .17 & .15 & .08 & $.22 *$ & .12 & 17 & .01 & .10 & الاجتماعي \\
\hline & & & & & & & & الاسري \\
\hline .11 & .15 & .46 & .04 & .24 & .10 & .90 & .36 & ارتباط بيرسون \\
\hline-.01 & .03 & -.05 & .11 & .02 & .00 & -.08 & -.00 & الاقتصادي \\
\hline & & & & & & & & \\
\hline .88 & .72 & .61 & .29 & .80 & .94 & .45 & .95 & ارتباط بيرسون \\
\hline .02 & .09 & -.05 & .15 & .10 & .17 & .00 & .09 & \\
\hline .79 & .41 & .60 & .14 & .35 & .11 & .97 & .37 & \\
\hline & & .05 & & & & .12 & & \\
\hline & & .59 & & & & .25 & & \\
\hline
\end{tabular}

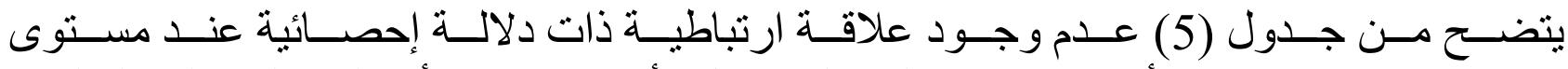
(a 10.01$)$

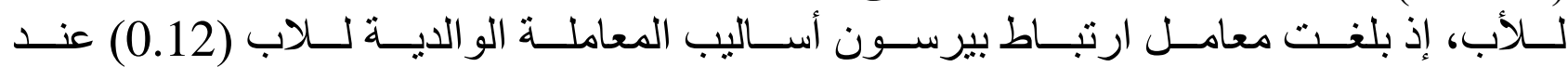

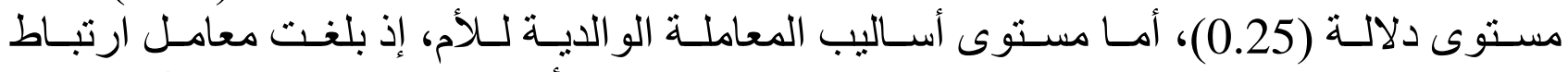

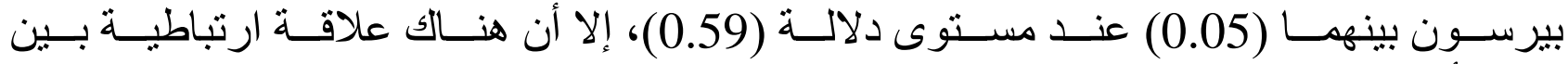
بعض أبعاد المقياسين.

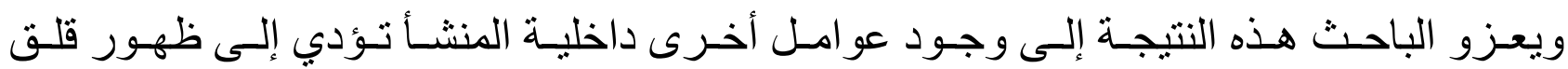

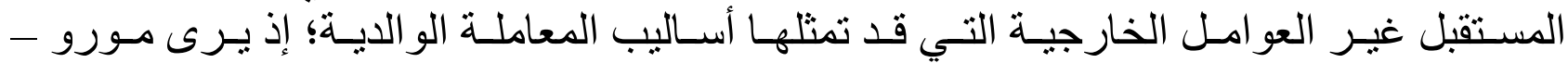

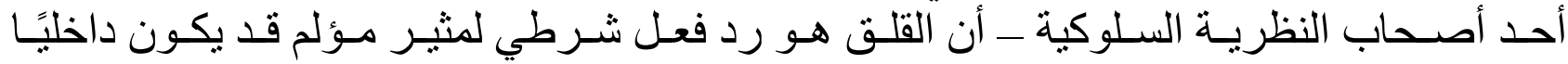

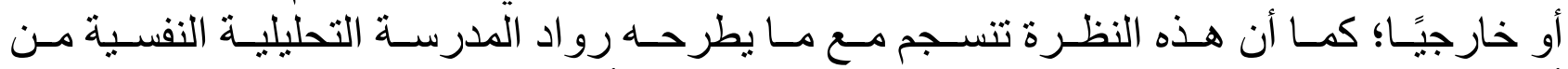

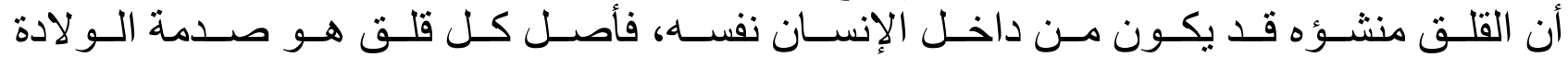

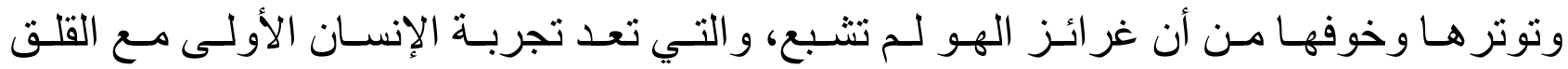

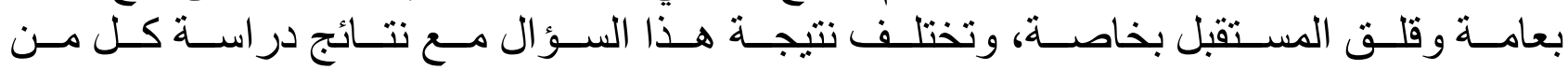

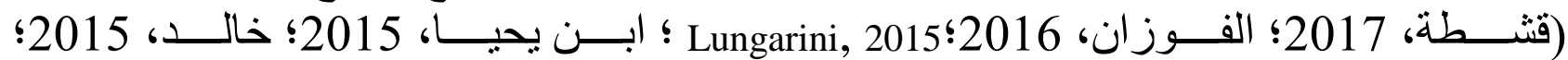
بعلى، 2013؛ حكيمة وأحمد، 2011؛ ألعز، 2010؛

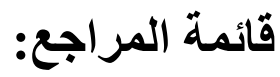

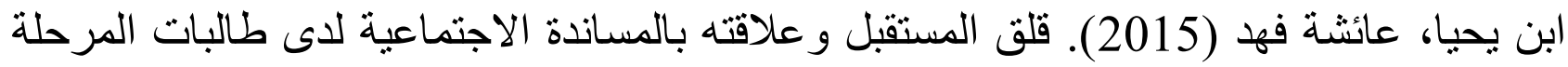

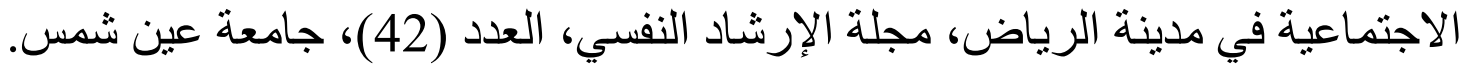


أبو العلاء، نجلاء مصطفى إسماعيل (2017). أساليب المعاملة الوالدية كما يدركها الأبناء

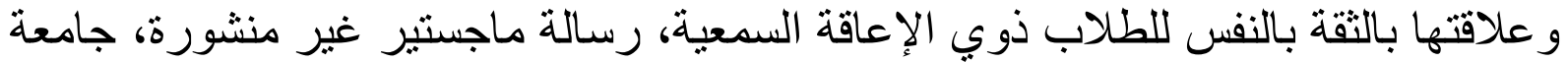

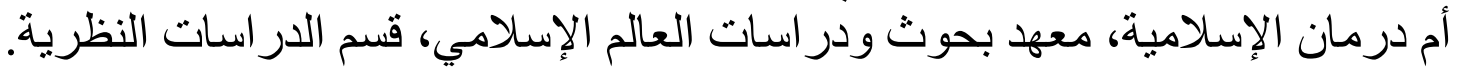

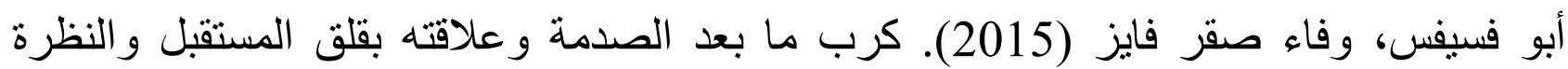

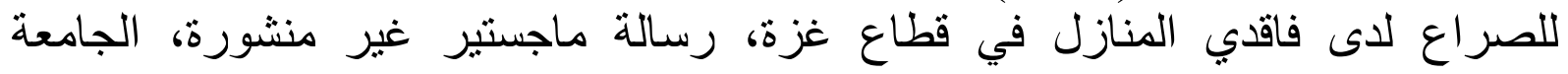
الإسلامية، كلية التربية، غزية الفئر

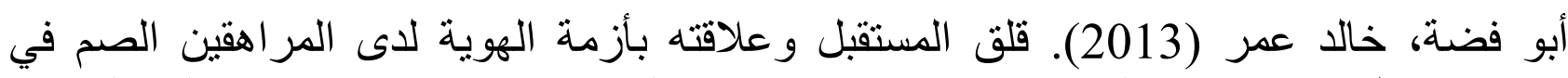
محافظات غزة، رسالة ماجستير غير منشورة، الجامعة الإسلامية (غزة)، الهانة كلية التربية، فلسطين. بخيت، فاطمة حسن (2017). سمة التدين و علاقتها بالمهار ات الاجتماعية لدى الطلاب المعاقين

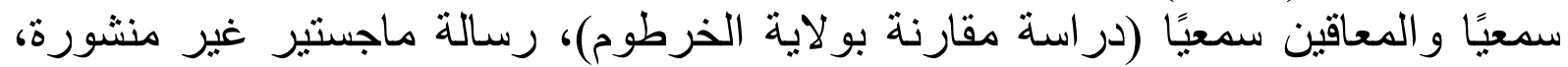

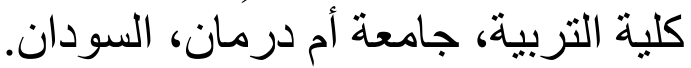

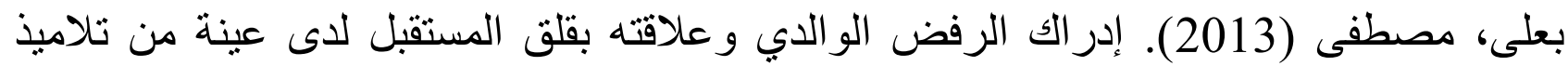

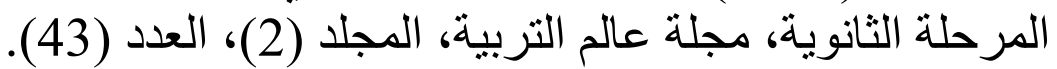

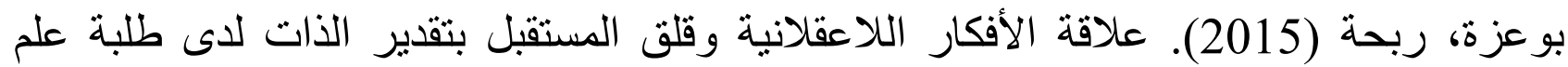

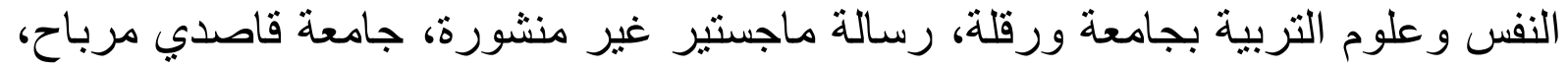

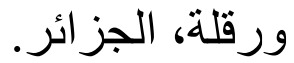

الجاجان، ياسر ونحيلي، علي (2016). در اسة الفروق في قلق المستقبل لدى طلبة كلية التربية في

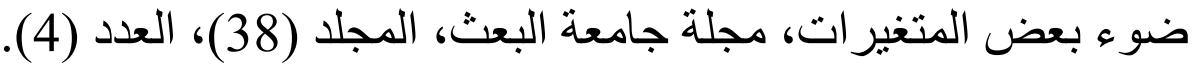

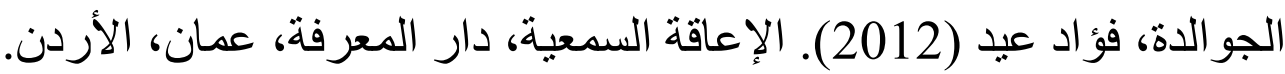

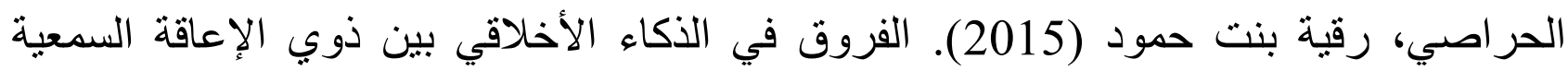

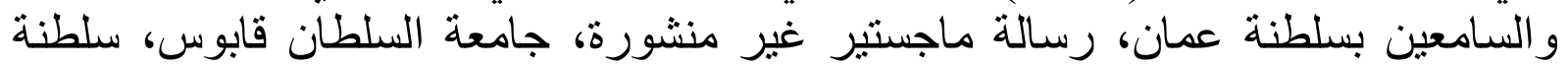

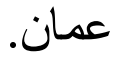

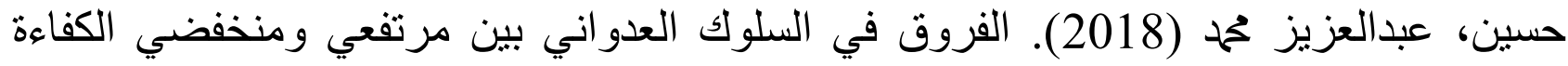

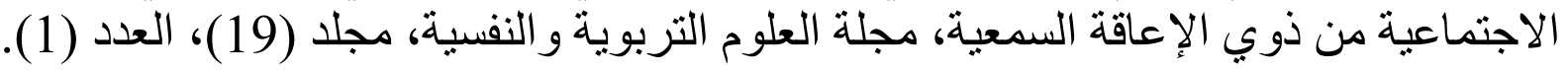

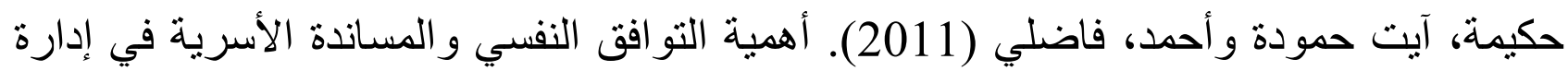

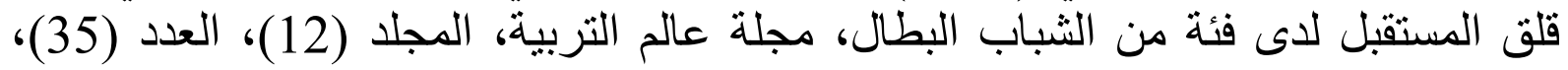
المؤسسة العربية للاستشار ات العلمية وتنمية الموارد البشرية.

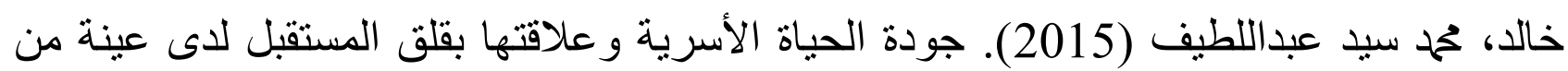

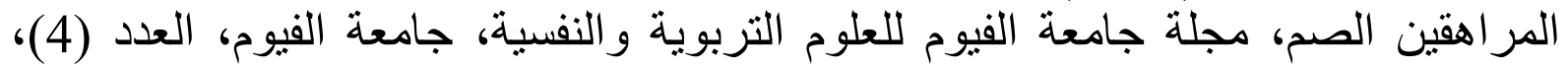

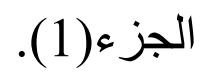

الرواحية، جيهان سالم محمد (2016). أساليب المعاملة الو الدية كما تدركها طالبات الصف الهف الثاني عثر و علاقتها بالتو افق النفسي في محافظة الداخلية، رسالة ماجستير غير منشورة، جامعة 


\section{نزوى، كلية العلوم والآداب، سلطنة عمان.}

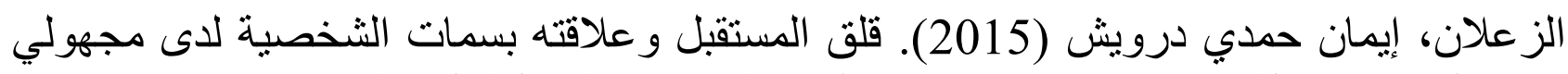

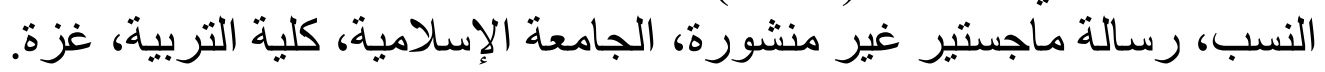
السليماني، أحمد سالم سيف (2017). أثر تقدير الذات على مفاهيم المو اطنة لدى الدئ المعاقين سمعيًًا

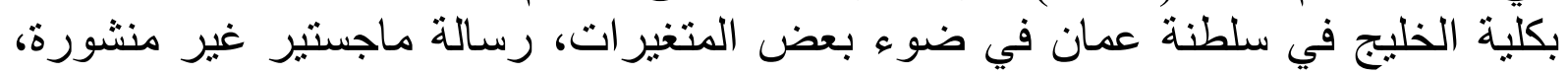
جامعة نزوى، سلطنة عمان.

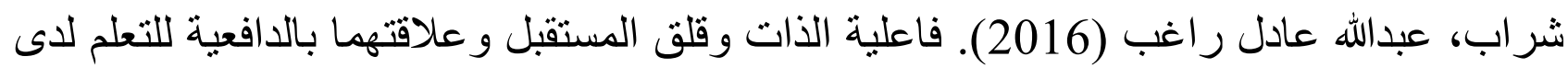

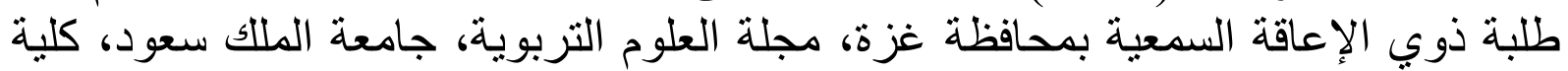

$$
\text { التربية، المجلد (28)، العدد (3) (3). }
$$

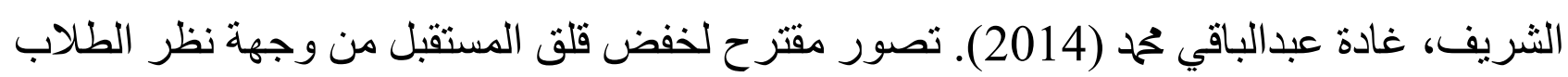

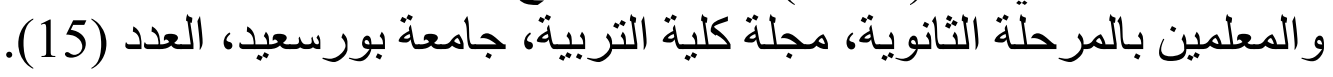

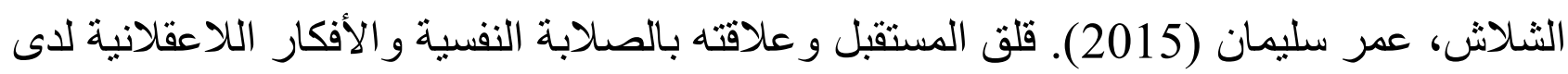

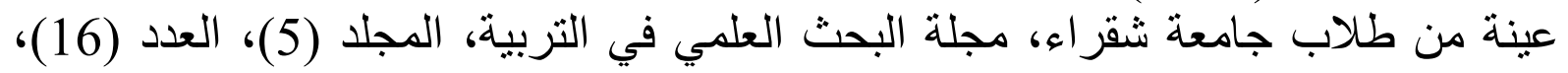
جامعة عين شمس، كلية البنات للآداب و العلوم و التربية.

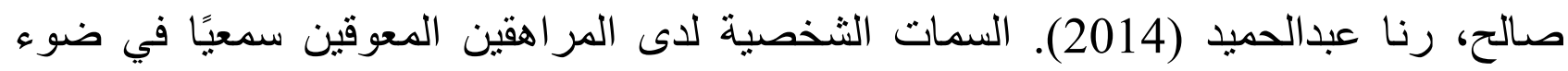
بعض المتغير ات، رسالة ماجستير غير منشورة، جامعة دمشت، كلية التربية.

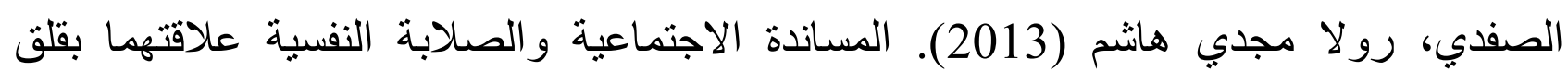

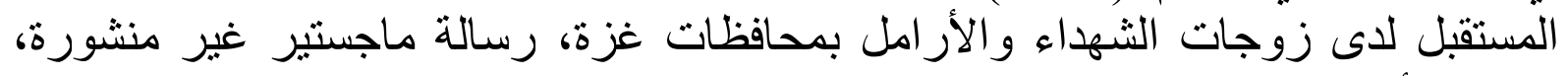

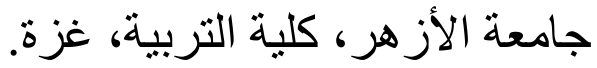

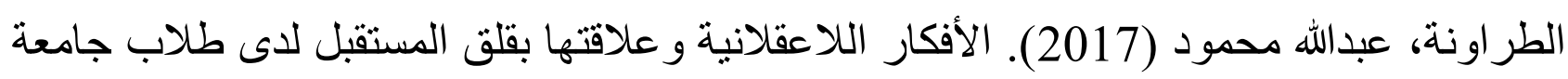
مؤنة، مجلة القر اءة والمعرفة، العدد (189)، الافكار (189)، جامعة عين شمس، كلية التربية.

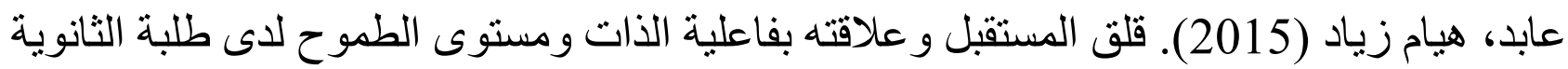
العامة في محافظة غزة، رساد رالة ماجستير غير منشورة، الجامعة الإسلامية، كلية التربية، غزة.

عدائكة، سامية وبوضياف، نادية وحنان، عدواني (2019). الاتجاهات الحديثة في التكنولوجيا

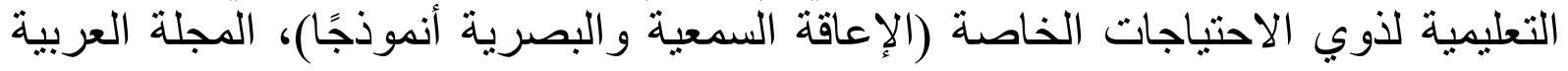

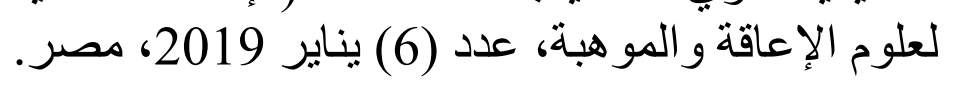

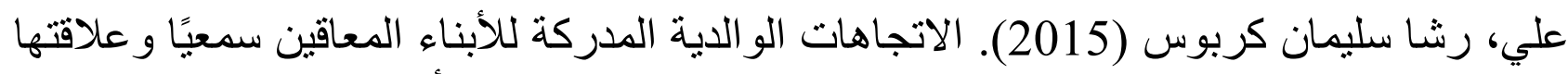

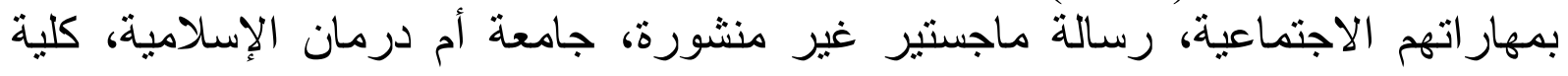
الدر اسات العليا.

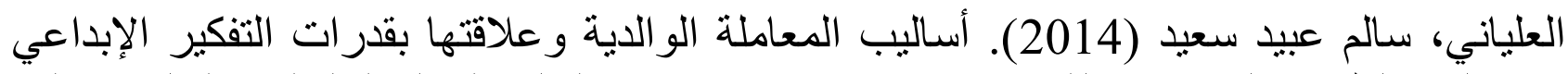
لذى الطلاب الصم، رسالة ماجستير غير منشورة، جامعة الباحة، المملكة العربية السعودية. العنزي، خالد الحميدي هدمول (2010). إدرالك القبول - الرفض الوالدي والأفكار اللاعقلانية 
وقلق المستقبل لدى عينة من طلاب جامعة الحدود الثمالية، رسالة دكتور اة غير منشورة، جامعة أم القرى، المملكة العربية السعودية.

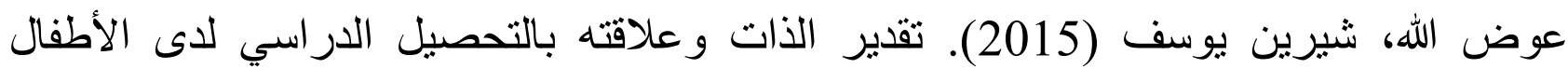
المعاقين سمعيًا بمعهد الأمل، رسالة ماجستير غير منشورة، كلية الدراسات العليا، جامعة الإلية

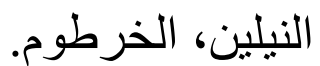

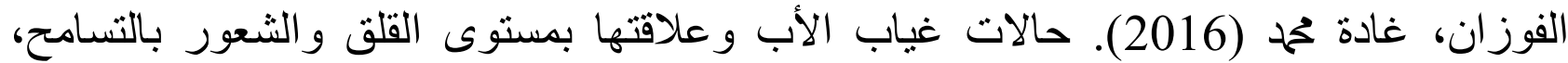
رسالة ماجستير غير منشورة، جامعة نايف للعلوم الأمنية، كلية العلوم الاجتماعية والإنية الإدارية، قسم علم النفس.

قتنطة، لمباء محهد (2017). الحرمان العاطفي الأبوي و علاقته بالاكتئاب وقلق المستقبل (دراسة

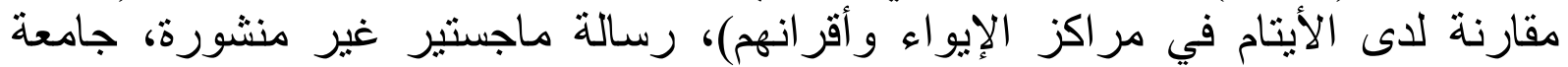

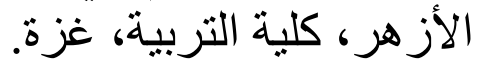

كلاب، نسرين خميس حمحل (2014). إثباع الحاجات النفسية وعلاقتها بقلق المستقبل لدى المر اهقين

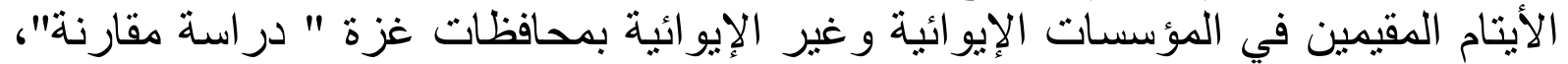

رسالة ماجستير غير منشورة، الجامعة الإسلامية، كلية التربية، غزية غزة الإنة

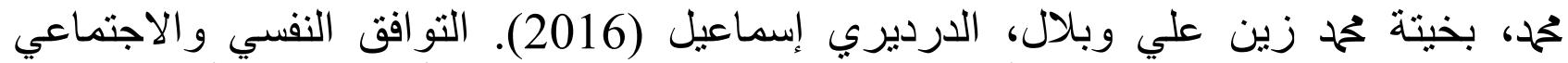

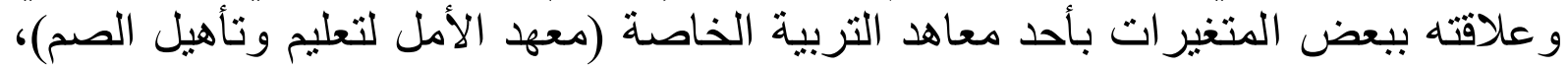
بولاية الخرطوم (منطقة الخرطوم 3)، مجلة العلوم التربوية، المجلد (17)، التهدة العدد (1).

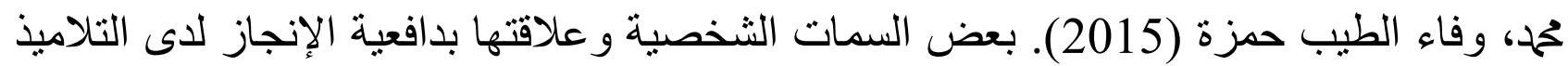

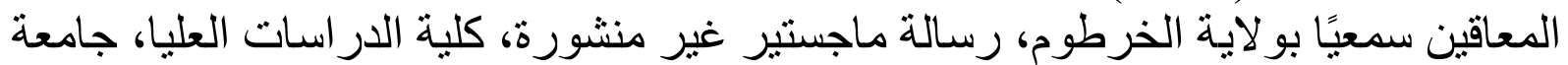

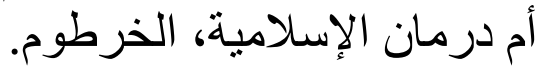

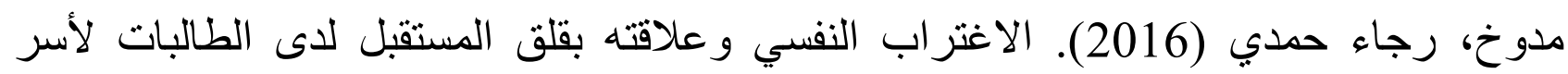

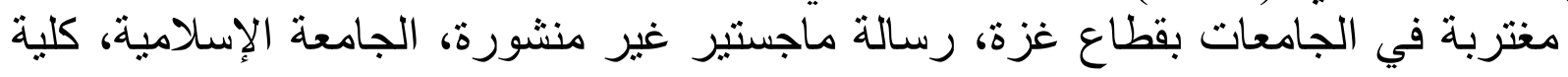

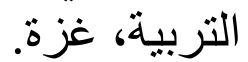

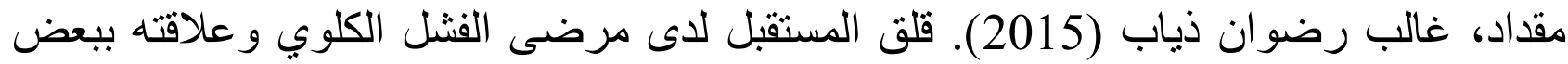
المتغيرات، رسالة ماجستير غير منشورة، الجامعة الإسلامية، كلية التربية، غزة التهائ

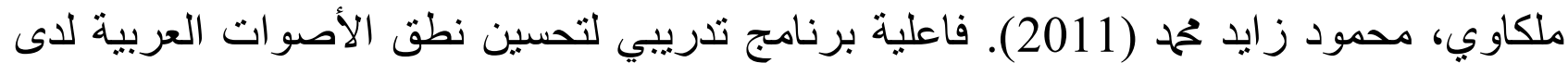

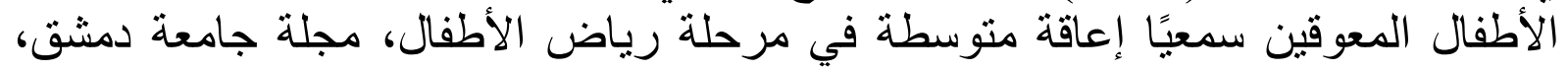

$$
\text { المجلد (27)، العدد (1-2). }
$$

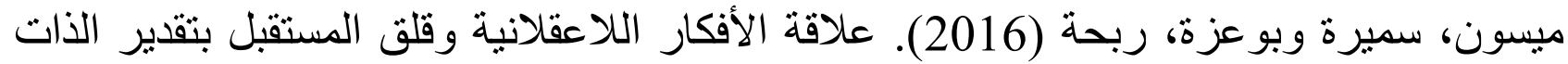

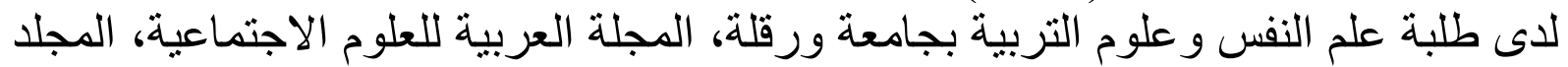
(1)، العدد (9)، المؤسسة العربية للاستشار ات العلية ولمية وتنمية الموارد البشرية.

\section{ARABIC REFERENCES IN ROMAN AIPHABET}

Abn Yahya, Eayishat Fahd (2015). Qalaq Almustaqbal Waealaqatih Bialmusanadat Alaijtimaeiat Ladaa Talibat Almarhalat Alaijtimaeiat Fi Madinat Alriyadi, Majalat Al'iirshad Alnafsii, Aleadad (42), Jamieat Eayan Shums. 
'Abu Aleala'i, Nujila' Mustafaa 'lismaeil (2017). 'Asalib Almueamalat Alwalidiat Kama Yudrikuha Al'abna' Waealaqatuha Bialthiqat Bialnafs Liltalab Dhwyi Al'iieaqat Alsameiati, Risalat Majsatayr Ghyr Manshurati, Jamieat 'Am Darman Al'iislamiati, Maehad Bihawth Wadirasat Alealam Al'iislamii, Qism Aldirasat Alnazariat.

'Abu Fasifis, Wafa' Saqr Fayiz (2015). Karb Ma Baed Alsadmat Waealaqatih Biqalaq Almustaqbal Walnazrat Lilsirae Ladaa Faqidi Almanazil Fi Qitae Ghazati, Risalat Majsatayr Ghyr Minshurat, Aljamieat Al'iislamiati, Kuliyat Altarbiati, Ghazat.

'Abu Fadat, Khalid Eumar (2013). Qalaq Almustaqbal Waealaqatih Bi'azmat Alhuiat Ladaa Almurahiqin Alsumi Fi Muhafazat Ghazati, Risalat Majsatayr Ghyr Minshurat, Aljamieat Al'iislamia (Ghzata), Kuliyat Altarbiati, Filastin.

Bakhit, Fatimat Hasan (2017). Simat Altadayn Waealaqatuha Bialmiharaat Alaijtimaeiat Ladaa Altullab Almueaqin Smeyana Walmueaqin Smeyana (Draasat Mqarnt Biwilayat Alkhartuma), Risalat Majstayr Ghyr Manshurati, Kuliyat Altarbiati, Jamieat 'Am Dirman, Alsuwdan.

Buealaa, Mustafaa (2013). 'lidrak Alrafd Alwalidii Waealaqatih Biqalaq Almustaqbal Ladaa Eayinat Min Talamidh Almarhalat Althaanawiati, Majalat Ealam Altarbiati, Almujalid (2), Aleadad (43).

Buezat, Rabha (2015). Ealaqat Al'afkar Allaaeqlaniat Waqalaq Almustaqbal Bitaqdir Aldhdhat Ladaa Tlbt Eilm Alnafs Waeulum Altarbiat Bijamieat Waraqlati, Risalat Majsatayr Ghyr Manshurat, Jamieat Qasidiin Murbahin, Waraqlata, Aljazayir.

Aljajani, Yasir Wanahili, Eali (2016). Dirasat Alfuruq Fi Qalaq Almustaqbal Ladaa Tlbt Kuliyat Altarbiat Fi Daw' Bed Almutaghayirati, Majalat Jamieat Albueth, Almajalid (38), Aleadad (4).

Aljawalidat, Fuad Eyd (2012). Al'iieaqat Alsameiatu, Dar Almuerifatu, Eiman, Al'urdunn.

Alharasiu, Raqiat Bnt Hamuwd (2015). Alfuruq Fi Aldhika' Al'akhlaqii Bayn Dhwyi Al'iieaqat Alsameiat Walsaamiein Bisiltanat Eumaan, Risalat Majsatayr Ghyr Manshurat, Jamieat Alsultan Qabaws, Saltanat Eaman.

Husayn, Eabdaleziz Muhamad (2018). Alfuruq Fi Alsuluk Aleudwanii Bayn Murtafiei Wamunkhafidi Alkafa'at Alaijtimaeiat Min Dhwyi Al'iieaqat Alsameiati, Majalat Aleulum Altarbawiat Walnafsiati, Mujalad (19), Aleadad (1).

Hakimat, Ayat Hamuwdat Wa'ahmad, Fadly (2011). 'Ahamiyat Altawafuq Alnafsii Walmusanadat Al'asriat Fi 'Iidarat Qalaq Almustaqbal Ladaa Fiat Min Alshabab Albitali, Majalat Ealam Altarbiati, Almujalid (12), Aleadad (35),

Almuasasat Alearabiat Lilaistisharat Aleilmiat Watanmiat Almawarid Albashariati.

Khalid, Muhamad Syd Eabdallatif (2015). Jawdat Alhayat Al'asriat Waealaqataha Biqalaq Almustaqbal Ladaa Eayinat Min Almurahiqin Alsim, Majalat Jamieat Alfayuwm Lileulum Altarbawiat Walnafsiati, Jamieat Alfium, Aleadad (4), Aljiz'(1).

Alruwahiat, Jihan Salim Muhamad (2016). 'Asalib Almueamalat Alwalidiat Kama Tudrikuha Talibat Alsafi Althany Eshr Waealaqatuha Bialtawafuq Alnafsii Fi Muhafazat Aldaakhliati, Risalat Majstayr Ghyr Manshurat, Jamieat Nazwaa, Kuliyat Aleulum Waladabi, Saltanat Eaman.

Alzaelanu, 'liman Hamdi Darwish (2015). Qalaq Almustaqbal Waealaqatih Basamat Alshakhsiat Ladaa Majhuli Alnisbi, Risalat Majsatayr Ghyr Minshurat, Aljamieat Al'iislamiati, Kuliyat Altarbiati, Ghazat.

Alsulaymani, 'Ahmad Salim Sayf (2017). 'Athar Taqdir Aldhdhat Ealaa Mafahim Almuatinat Ladaa Almaeaqin Smeyana Bikaliat Alkhalij Fi Saltanat Eamman Fi Daw' Bed Almutaghayirati, Risalat Majsatayr Ghyr Manshurat, Jamieat Nazwaa, Saltanat Eaman.

Alfawzan, Ghadat Muhamad (2016). Halat Ghiab Al'abi Waealaqatiha Bimustawaa Alqalaq Walshueur Bialtasamuhi, Risalat Majsatayr Ghyr Manshuratin, Jamieat Nayif Lileulum Al'amniati, Kuliyat Aleulum Alaijtimaeiat Wal'iidariati, Qism Eilm Alnafsa.

Qishtat, Limia' Muhamad (2017). Alhirman Aleatifii Al'abawii Waealaqatuh Bialaiktiaab Waqalaq Almustaqbal (Draasat Mqarnt Ladaa Al'aytam Fi Marakiz Al'iiwa' Wa'aqranihima), Risalat Majsatayr Ghyr Manshurat, Jamieat Al'azhari, Kuliyat Altarbiati, Ghazat.

Kulabu, Nasrin Khamis Muhamad (2014). 'lishbae Alhajat Alnafsiat Waealaqatiha Biqalaq Almustaqbal Ladaa Almurahiqin Al'aytam Almuqimin Fi Almuasasat Al'iiwayiyat Waghayr Al'iiwayiyat Bimuhafazat Ghaza " Dirasat Muqarint", Risalat Majsatayr Ghyr Minshurat, Aljamieat Al'iislamiati, Kuliyat Altarbiati, 
Ghazat. Muhmidun, Bikhaytat Muhamad Zayn Eali Wabilal, Aldardiri 'lismaeil (2016)

. Altawafuq Alnafsia Walaijtimaeia Waealaqatah Bibaed Almutaghayirat Bi'ahd Mueahid Altarbiat Alkhasa (Meahid Al'amal Litaelim Watahil Alsm), Biwilayat Alkhartum (Mnataqat Alkhartum 3), Majalat Aleulum Altarbawiat, Almajalid (17), Aleadad (1).

Muhmid, Wafa' Altayib Hamza (2015). Bed Alsmat Alshakhsiat Waealaqatiha Bidafieiat Al'iinjaz Ladaa Altalamidh Almueaqin Smeyana Biwilayat Alkhartumi, Risalat Majsatayr Ghyr Manshurati, Kuliyat Aldirasat Aleulya, Jamieat 'Am Darman Al'iislamiati, Alkhartum.

Mudawkhun, Raja' Hamduy (2016). Alaightirab Alnafsii Waealaqatuh Biqalaq Almustaqbal Ladaa Altaalibat Li'asr Mughtarabat Fi Aljamieat Biqitae Ghazati, Risalat Majsatayr Ghyr Minshurat, Aljamieat Al'iislamiati, Kuliyat Altarbiati, Ghazat.

Maqdad, Ghalib Ridwan Dhiab (2015). Qalaq Almustaqbal Ladaa Mardaa Alfashal Alkulawii Waealaqatih Bibaed Almutaghayirati, Risalat Majsatayr Ghyr Minshurat, Aljamieat Al'iislamiati, Kuliyat Altarbiati, Ghazat.

Malkawi, Mahmud Zayid Muhamad (2011). Faeiliat Barnamaj Tadribiun Litahsin Natq Al'aswat Alearabiat Ladaa Al'atfal Almueawaqin Smeyana 'lieaqat Mutawasitat Fi Marhalat Riad Al'atfali, Majalat Jamieat Dimushq, Almajalid (27), Aleadad (1-2).

Misun, Samirat Wabuezat, Rabha (2016). Ealaqat Al'afkar Allaeqlaniat Waqalaq Almustaqbal Bitaqdir Aldhdhat Ladaa Tlbt Eilm Alnafs Waeulum Altarbiat Bijamieat Waraqlat, Almajalat Alearabiat Lileulum Alaijtimaeiati, Almujalid (1), Aleadad (9), Almuasasat Alearabiat Lilaistisharat Aleilmiat Watanmiat Almawarid Albashariati.

\section{REFERENCE LIST}

Lungarini, A. (2015). Parenting Styles and Their Relationship with Anxiety in Children. Master. University of Rhode Island.

Parhoon, K., Hassanzadeh, S., Parhoon, H. and Movallali, G. (2014). Needs Assessment of Student with Hearing Impairment in Inclusive School. International Journal of Academic Research in Progressive Education, 3(2).

Saleem, S. (2017). The Mainstream Problems Coping Students with Hearing Disability in Najran Region. Journal of Education and Practice, 8(14).

Santoso, D. and Rizkiana, A. (2018). Positive Thinking on Future Anxietyon Hearing Impaired College Students. Advances in Social Science, Education and Humanities Research (ASSEHR), 304. 